Published in final edited form as:

Gastroenterol Clin North Am. 2015 June ; 44(2): 203-231. doi:10.1016/j.gtc.2015.02.001.

\title{
Epidemiology of Barrett's Esophagus and Esophageal Adenocarcinoma
}

\author{
Thomas M. Runge ${ }^{1}$, Julian A. Abrams ${ }^{2}$, and Nicholas J. Shaheen ${ }^{1}$ \\ ${ }^{1}$ University of North Carolina at Chapel Hill, Center for Esophageal Diseases and Swallowing, \\ Division of Gastroenterology and Hepatology, Chapel Hill, NC \\ ${ }^{2}$ Division of Digestive and Liver Diseases, Columbia University Medical Center, New York, NY
}

\begin{abstract}
Barrett's esophagus (BE) is a common condition, and is the precursor to esophageal adenocarcinoma, a disease with increasing burden in the western world, especially in Caucasian males. The incidence of $\mathrm{BE}$ increased dramatically during the late- $20^{\text {th }}$ century and incidence estimates continue to increase, with a prominent male:female ratio. The prevalence is between 0.5 -2.0 percent. A number of anthropomorphic and behavioral risk factors exist for BE including obesity and tobacco smoking, but GERD is the strongest risk factor, and the risk is more pronounced with long-standing GERD. Esophageal adenocarcinoma (EAC) is the most common form of esophageal cancer in the U.S. Risk factors include GERD, tobacco smoking, and obesity, while NSAIDs and statins may be protective. A major factor predicting progression from nondysplastic BE to EAC is the presence of dysplastic changes seen on esophageal histology, although a number of issues limit the utility of dysplasia as a marker for disease. Length of the involved BE segment is another risk for progression to high-grade dysplasia and cancer.

Biomarkers have shown promise, but none are approved for clinical use.
\end{abstract}

\section{Introduction}

Barrett's esophagus (BE) is a condition in which the typical squamous epithelium of the esophageal mucosa is replaced with columnar intestinal epithelium ${ }^{1,2} \mathrm{BE}$ is a known precursor to the development of esophageal adenocarcinoma (EAC), a malignancy with a dramatically increasing incidence over the past 40 years. ${ }^{3-5}$ The risk of EAC among

\footnotetext{
(C) 2015 Published by Elsevier Inc.

Corresponding Author: Nicholas J. Shaheen, MD, MPH, Professor of Medicine and Epidemiology, Chief, Division of Gastroenterology and Hepatology, University of North Carolina School of Medicine, CB\#7080, Chapel Hill, NC 27599-7080, Phone: (919) 966-2513, Fax: (919) 843-2508.

Julian Abrams, MD, MS, Assistant Professor of Medicine and Epidemiology, Division of Digestive and Liver Diseases, $622 \mathrm{~W} 168^{\text {th }}$ St, PH 7W-318D, New York, NY 10032, ja660@ cumc.columbia.edu

Thomas Runge, MD MPH, Gastroenterology Research Fellow, Division of Gastroenterology and Hepatology, University of North Carolina School of Medicine, CB\#7080, Chapel Hill, NC 27599-7080, Phone: (919) 966-2514, thomas.runge@ unchealth.unc.edu

This is a PDF file of an unedited manuscript that has been accepted for publication. As a service to our customers we are providing this early version of the manuscript. The manuscript will undergo copyediting, typesetting, and review of the resulting proof before it is published in its final citable form. Please note that during the production process errors may be discovered which could affect the content, and all legal disclaimers that apply to the journal pertain.

Dr. Runge has no conflicts to declare.
} 
patients with BE is estimated to be $30-125$ fold greater than that of the general population. ${ }^{6}$ Endoscopically, the prevalence of $\mathrm{BE}$ has been estimated at $1-2 \%$ in all patients receiving endoscopy for any indication, and anywhere from 5 to $15 \%$ in patients with symptoms of GERD. ${ }^{7}$ EAC, though uncommon, has a poor prognosis, and is associated with a 5 -year survival rate of $<20 \% 8,9$

The incidence of $\mathrm{EAC}$ in patients with $\mathrm{BE}$ is considerably higher than that in the general population, but only a minority of BE patients develop EAC, with annual risk estimated at $0.1-0.5 \% .^{10,11}$ Reasons for the meteoric rise in the incidence of EAC are not entirely known. However, risk factors for the development of BE and EAC have been identified. Similarly, risk factors for the progression of BE to EAC have also been identified, and will be discussed here.

\section{Epidemiology of Barrett's Esophagus}

\section{Prevalence and Incidence of BE}

Barrett's esophagus primarily affects older adults in the developed world. The true prevalence in living adults is difficult to ascertain, because individuals with Barrett's are often asymptomatic and do not seek care. One of the earliest estimates of the prevalence of BE was via an autopsy study. ${ }^{12}$ Cameron and colleagues estimated a prevalence of long segment BE of 376 cases per 100,000 , or roughly $0.4 \%$ of the population, and suggested that only a small minority of cases were detected clinically. ${ }^{12}$ Population-based studies have provided estimates of the prevalence of BE in the general public. A Swedish study by Ronkainen et $\mathrm{al}^{13}$ estimated the prevalence of BE by performing upper endoscopy on 1000 randomly selected adults. These investigators found BE in $16(1.6 \%)$ of the individuals, with 5 subjects $(0.5 \%)$ in their study demonstrating long-segment disease. ${ }^{13}$

Tertiary care center endoscopy studies have also attempted to estimate the prevalence of BE. Rex et al ${ }^{14}$ performed upper endoscopy in 961 individuals presenting for routine screening colonoscopy. These investigators found an overall prevalence of BE of $6.8 \%$, or 65 of 961 individuals, of whom $12(1.2 \%)$ had LSBE. In patients who reported heartburn, the prevalence was slightly higher at $8.3 \%$, but the majority of patients $(54 \%)$ who were found to have $\mathrm{BE}$ reported no reflux symptoms. These estimates may be higher than the prevalence in the general population, as this tertiary center population of volunteers may have had more GERD than a true random sample of the adult population. Zagari et al analyzed 1033 patients originally identified as part of a large multicenter cross-sectional study on gallstone disease. ${ }^{15}$ Of these patients, $1.3 \%$ (13) had histologically confirmed BE, while $0.2 \%$ (2) had long-segment BE. These estimates suggest that the prevalence of BE is between $0.5-2 \%$ of unselected individuals. In individuals with reflux symptoms, prevalence estimates are more variable (Table 1), ranging from $5-15 \% 16$.

Given that the utilization of endoscopy is dependent on the patient's socioeconomic status, access to care, and other non-medical factors, the incidence of BE has historically been very difficult to ascertain. However, the incidence of endoscopically-detected BE appears to have increased dramatically over the past 30 years, a finding partially attributable to the increasing frequency of endoscopy during the same period. ${ }^{17}$. Data from the U.K. ${ }^{18}$ and the 
Netherlands ${ }^{19}$ however, suggest that incidence rate of BE have increased even after controlling for increasing endoscopy rates. These estimates place the increase in BE incidence at near $65 \%$ between 1997 and $2002^{19}$ and $159 \%$ between 1993 and 2005 .

Alarmingly, the greatest proportional increase in BE diagnosis was in those under age 60, in agreement with other work from Europe. ${ }^{18}$

\section{Age, Sex, and Ethnic Variations in BE}

Males, especially Caucasian males, have a strong predilection for the development of BE, with a male:female ratio of 2-3:1 in most studies (see Table 2). ${ }^{1,20}$ Age at diagnosis can vary widely, as many individuals are asymptomatic and undergo diagnostic endoscopy for other reasons. ${ }^{21} \mathrm{BE}$ on average is diagnosed in the $6^{\text {th }}-7^{\text {th }}$ decade of life, but may develop far earlier ${ }^{22}$. In addition to the greater overall prevalence of BE in men, there is evidence that males develop the disease earlier than females. From a British endoscopy center, Van Blankenstein et al reviewed endoscopy records and histology reports of individuals who received upper endoscopy at a single center ${ }^{22}$. Males on average developed BE about 20 years earlier than females in that study. The overall ratio of BE cases was 2:1 favoring males, but in younger adults, the ratio of men to women approached $4: 1{ }^{22}$ A similar trend to early development of BE in men was seen in follow-up studies from Europe. ${ }^{18,} 19$ Caucasians in general are disproportionately affected compared to other races. ${ }^{23}$ In a large cross-sectional study, Ford et al, in a sample from the U.K., found that Caucasians had significantly higher prevalence of BE compared to Asians or Afro-Caribbean. In that population, LSBE was found in $2.9 \%$ of Caucasians, compared to $0.31 \%$ of Asians and $0.2 \%$ of Afro-Caribbeans ${ }^{24}$.

Studies assessing BE prevalence in Latinos also demonstrate that BE is considerably less prevalent in Latinos compared to Caucasians. In a large study by Abrams et al, the prevalence of BE was significantly lower among those of Latino background than among Caucasians $(1.7 \% \text { vs. } 6.1 \%)^{25}$. Other studies have corroborated variations in BE prevalence among ethnic groups living in the same country, possibly suggesting an effect of yetunrecognized polygenetic factors across different ethnicities.

Multiple environmental factors are strongly associated with BE. These factors, such as obesity, GERD, and hiatal hernias are more common in developed countries. However, genetic factors are likely also at play. Work from twin studies suggests that symptoms of GERD, even when adjusted for obesity and other clinical factors, are more concordant in monozygotic twins than dizygotic twins. ${ }^{26}$

\section{Selected risk factors for BE development}

GERD-GERD is a central risk factor for BE development. Numerous case-control studies have shown that individuals with GERD are 6-8 times more likely to have BE, and the propensity to develop BE increases with more severe symptoms (see Table 1) ${ }^{27-29}$ Longer duration of GERD may create an environment conducive to the development of $\mathrm{BE}^{30}$ However, the presence of reflux symptoms is neither sensitive nor specific for pathologic acid reflux 31,32 , and indeed symptom severity does not correlate well with BE risk. ${ }^{33,34}$ Some work has suggested that patients with more significant symptoms may be less likely to 
have $\mathrm{BE},{ }^{35}$ perhaps because of impaired acid sensitivity of the columnar metaplasia compared to normal squamous epithelium. However, longer duration of GERD symptoms predicts increased likelihood of BE. ${ }^{27}$. A systematic review on the association between symptoms and BE found no association between reflux symptoms and SSBE (OR 1.15, 95\% CI: 0.8 - 1.7) but found increased odds of LSBE in those with reflux symptoms (OR 4.92, 95\% CI: 2.0, 12.0). ${ }^{36}$ Since screening programs target both SSBE and LSBE, significant limitations in using symptom severity remain. When patients with Barrett's are compared to those without, the BE patients have abundant evidence of aberrant acid exposure -longer episodes of acid exposure, and lower $\mathrm{pH}$, and also weak peristaltic contractions and decreased baseline LES tone. ${ }^{37,38}$

While epidemiologic data suggest that gastric acid suppression with PPIs may reduce the chance of developing dysplasia and cancer ${ }^{39}$, the impact PPI use has on development of BE is unknown. Among the many adults who suffer from GERD, only a minority will develop $\mathrm{BE}$. The prevalence of $\mathrm{BE}$ among those with reflux symptoms is higher than that of the general population, but the relationship is not fully explained by GERD. Obesity may be a common mediator of both GERD and BE. Central adiposity is known to predispose to hiatal hernia development, ${ }^{7}$ increased GERD symptoms ${ }^{40}$ and even to directly cause LES relaxations ${ }^{41}$

In summary, reflux is associated with GERD. However, symptoms of reflux cannot reliably distinguish those with increased acid reflux from those without. It is likely that a genetic mileu predisposing to the development of BE combined with prolonged acid exposure and mutagenic events, including oxidative stress, may act synergistically in patients who develop EAC.

Obesity-Obesity, measured by BMI and central adiposity, has been studied extensively as a risk factor for BE. The incidence of BE and EAC have risen dramatically in the past 40-50 years in Western societies, concurrent with rapid increases in the rate of obesity. From 1976 to 1991 , the prevalence of obesity at all ages rose from $25 \%$ to $33 \%$, and it now approaches $35 \%$ in adults. ${ }^{42}$ Obesity can be assessed in several ways. High body mass indices and especially central adiposity have been shown to have a significant association with BE. A 2009 meta-analysis that included 11 observational studies showed an increase in the risk of $\mathrm{BE}$ (OR 1.4) in patients with a BMI $>30 \mathrm{~kg} / \mathrm{m} 2$ compared to those with BMI $<30 \mathrm{~kg} / \mathrm{m} 2.43$ Patients with BE have been shown to have higher BMIs than either general controls or individuals with GERD but not BE. ${ }^{44,45}$

Because BMI does not take into account the distribution of body fat, the estimated risk increase in the obese may actually be poorly estimated by BMI measurements. In fact, more recent work has shown that central adiposity, rather than BMI, may be the true driver of increased BE risk. Edelstein et al, in a case control study in 2007, found that the overall risk of BE was significantly greater in those with high WHR (OR 2.4); the risk of LSBE in these patients was even higher (OR 4.3). ${ }^{44}$ A pooled analysis by Kubo et al found that waist circumference, as a proxy measure for central adiposity, increased risk for BE for males (OR 2.24) and females (OR 3.75). ${ }^{46}$ The impact of obesity on BE risk may vary by race as well. In a U.S. case-control study, Kramer et al studied the effect of BMI and waist-to-hip ratio 
(WHR) on BE prevalence, and found that the relationship between WHR and BE was strongest and most significant in Caucasians (OR 2.5), while in African-Americans and Latinos the associations were not significant. ${ }^{23}$ Because of the strength of the relationship between WHR and BE was stronger in Caucasians, it was suggested that other ethnic groups could potentially carry as-yet unrecognized genes that protect against BE development. ${ }^{23} \mathrm{It}$ is possible that the overwhelming male predominance among EAC cases could be explained in part by the fact that overweight males distribute fat preferentially to their trunk, and this central adiposity drives the risk increase. ${ }^{47}$

Alcohol-Alcohol use has been studied extensively as a possible risk factor for BE. ${ }^{13,27,48-50}$ multiple studies have shown no association between the two, but results have been variable. ${ }^{48,49,51}$ Some work has suggested an inverse correlation between wine intake and BE risk. ${ }^{48}$ The most robust evidence we have on the issue comes out of the BEACON consortium, in which the data from 5 studies were pooled to assess risk of alcohol use. ${ }^{50}$ Among 1,028 cases and 1,282 controls, alcohol use was stratified by gender and by number of drinks per day. There was a borderline significant inverse correlation between BE and any degree of alcohol intake (OR 0.77, 0.60-1.00). Drinking 3 to $<5$ drinks per day was associated with a statistically significant reduction in BE risk (OR 0.57, 0.38-0.86), but with more or less alcohol consumed no statistically significant results were found (although there was a trend toward an inverse relationship). When assessing beverage-specific data, wine consumption was associated with an inverse risk of BE (OR 0.71) ${ }^{46,48}$

At this point the preponderance of evidence supports no association between alcohol intake and $\mathrm{BE}$ risk. What was at one time thought to be a minor risk factor for BE now appears to confer no additional risk at all. Alcohol might indeed be protective, but in order to fully answer this question, more data are needed.

Cigarette Smoking - The majority of studies have found an association between cigarette smoking and an increased risk of developing BE. ${ }^{52,53}$ A pooled analysis of 5 case-control studies found a consistent increase in risk of BE over several pack-year cutpoints, with ORs ranging from $1.44-1.99$ (figure 1) ${ }^{53}$ However, there was significant heterogeneity between studies, and exclusion of a single study yielded pooled ORs with a higher magnitude across all exposure groups, ranging from 1.75 to 2.89 , with an average OR of $2.09 .{ }^{53}$ To explore a possible synergistic effect between GERD and tobacco use in the genesis of BE, these investigators conducted additional modeling to assess the concurrent effects of smoking and GERD. ${ }^{53}$ They found that the OR of Barrett's increased significantly when both GERD and smoking were present, compared to when smokers did not have GERD.

However, not all studies have identified smoking as a risk factor for BE. Thrift et al ${ }^{51}$ studied 258 patients with BE in a case-control study from Houston. These patients were compared to 2 control groups: one group was composed of patients receiving elective EGD for any indication, and the other was composed of primary care patients undergoing screening colonoscopy. These researchers found no association between smoking and BE in either group, even when stratified by pack-year exposures, length of time smoking, or number of cigarettes/day. In a prospective study design, Steevens et al found ORs of 1.33 in former smokers and 0.93 in former smokers compared to controls. ${ }^{49}$ In conclusion, smoking 
appears to increase risk of BE, but there is wide variability in risk estimates. Further study may clarify the precise role of tobacco in $\mathrm{BE}$ pathogenesis.

Helicobacter pylori-Helicobacter pylori (Hp) infection causes chronic gastritis, PUD, and gastric adenocarcinoma. Hp is known to have a strong association with intestinal metaplasia in the body and antrum of the stomach. ${ }^{54}$ Temporal associations have been made between the decreasing prevalence of $\mathrm{Hp}$ infection in developed countries and the increasing prevalence of EAC. ${ }^{55}$ Corley et al showed that $\mathrm{Hp}$ was inversely associated with BE (OR 0.42 ) in a case-control study design. ${ }^{56}$ While the mechanisms underlying this inverse association are not fully understood, they may relate to decreased acid production in the setting of Hp infection (especially with associated atrophic gastritis) or via alterations in the microbiome.

Different strains of $\mathrm{H}$. pylori may have different abilities to induce risk. The presence of the cytotoxin-associated gene ( $\mathrm{CagA})$ identifies Hp strains more likely to induce gastritis, more extensive gastric inflammation, and gastric cancer. ${ }^{57}$ Vaezi et al addressed the role of $\mathrm{Hp}$ in a case control study, and found that patients with BE identified at endoscopy were about 3fold less likely to be colonized by CagA positive strains than were controls who did not have BE. ${ }^{58}$ However, contradictory findings were noted in a 2009 meta-analysis by Wang et al. ${ }^{59}$ Among included studies using endoscopically normal controls, the prevalence of $\mathrm{Hp}$ in controls was greater than that in $\mathrm{BE}$, but among those that use healthy blood donors as controls, BE patients more frequently had Hp infection. The result was a non-significant slight trend toward less Hp infection in patients with BE. ${ }^{59}$ The authors cited a need for further study with well-matched cases and controls to make robust conclusions about an association between Hp and BE.

\section{Other Possible Risk Factors}

Recently, several other possible risk factors for BE have been studied. Low birth weight (LBW) has been posited as a possible risk factor for BE given the apparent association between preterm birth and systemic inflammation. ${ }^{60}$. Forssell et al ${ }^{61}$ have shown from a Swedish birth cohort that prematurity is associated with the risk of developing esophagitis, a relationship that is most pronounced among those who are small for gestational age (OR 2.5) or who are born at $\leq 32$ weeks gestation (OR 6.7 ${ }^{61}$. Follow-up research by this group has suggested that the risk of BE was significantly increased in those with the lowest birth weights (OR 8.2) $)^{62}$ The risk of EAC appears to be increased with reduced gestational time, but the magnitude of effect is smaller (OR 1.1). ${ }^{63}$

Other factors associated with a proinflammatory state, such as obstructive sleep apnea (OSA) and the metabolic syndrome, appear to increase the risk of BE as well. In a casecontrol study, Leggett et al found that OSA was associated with an increased risk of BE (OR 1.8), after controlling for GERD and obesity. ${ }^{64}$ Increased levels of adipokines and cytokines have also been found in BE patients compared to controls. ${ }^{65}$ These inflammatory markers may be the intermediaries partially responsible for increased BE risk seen in those with central obesity, OSA, or GERD. 


\section{Epidemiology of Esophageal Adenocarcinoma}

\section{Prevalence and incidence of EAC}

Esophageal adenocarcinoma was once a rare form of esophageal malignancy. Surgical series in the early $20^{\text {th }}$ century showed that esophageal adenocarcinoma made up only $0.8-3.7 \%$ of all esophageal malignancies. ${ }^{66}$ However, by 1990, esophageal adenocarcinoma overtook squamous cell carcinoma of the esophagus, and is now the more common of the two in developed nations. ${ }^{67}$ Esophageal adenocarcinoma continues to increase in incidence (Figure 2, Figure 3) In 2014, there are expected to be 18,170 new esophageal cancers diagnosed in the U.S. ${ }^{6}$ About 15,000 individuals will die from esophageal cancer in 2014, and more than half of these will be from EAC. ${ }^{68,} 69$

\section{Age, Sex, and Ethnic Variations}

Esophageal cancer in general affects males in a 4:1 ratio compared to females. ${ }^{68}$ With EAC specifically, incidence is highest in Caucasian men, with a male-female ratio in Caucasians that approaches 8:170-72. The reported incidence of esophageal adenocarcinoma has risen dramatically over the past $30-40$ years ${ }^{3}$ By some estimates the incidence has increased from $300 \%$ to $500 \%$ over this time ${ }^{2}$, or by $10 \%$ annual increase in males, and between 5 and $7 \%$ annually in females ${ }^{73}$ In the U.S. from 1975 - 2006, the incidence of EAC increased 7-fold, an increase greater than that of any other major malignancy. ${ }^{74} \mathrm{Among}$ women, rates of EAC increased from 0.17 per 100,000 in $1975-1979$ to 0.74 per 100,000 in $2000-2004 .^{73}$ With EAC similar increases have been seen in the Latino population of the U.S. ${ }^{73}$ Fewer analyses have been done on African-American males or females often because of significantly lower numbers of reported cases of disease, yielding unstable estimates of risk. ${ }^{75}$ In the last quarter of the $20^{\text {th }}$ century, males $>65$ years of age saw the greatest increase in incidence of EAC, about $600 \% .^{76}$ Similar increases have been seen in European and some Asian populations as well. ${ }^{75,77}$ More recent data suggest that when separated by stage of disease at diagnosis, incidence of localized EAC have slowed while distant and regional cases have continued a rapid ascent (figure 3 ). ${ }^{72,76}$

Multiple studies assessing SEER data have suggested a ratio of EAC cases in Caucasians to African-Americans of approximately 5:1. ${ }^{71}$ These results parallel data on the prevalence of both erosive esophagitis and BE in Caucasians versus African-Americans, in which rates are significantly higher in Caucasians. ${ }^{25,} 78$ The increased incidence in EAC among Caucasians is somewhat counterintuitive, in that African-Americans, Caucasians and Asians report a similar prevalence of heartburn. ${ }^{71,78}$ Similarly, across multiple races, women in general often have fewer complications of GERD, whereas men are more likely to have erosive disease, BE, or EAC. ${ }^{70}$

The greatest gender disparity in EAC cases is seen in Caucasians, with an 8:1 ratio. In African-Americans, a 3:1 ratio is seen, and in Latinos, there is a 7:1 predominance of males compare to females. ${ }^{71}$ Other work has placed male-to-female ratios for Latinos even higher than those of Caucasians in some age groups. ${ }^{70}$

Recent research suggests that age-related incidence rates show similar patterns in different ethnic groups, and that older individuals are disproportionately affected. Nordenstedt et al, 
in an analysis of SEER data, showed that incidence of EAC peaks in the 70 year and older category in Caucasians, African-Americans, and Latinos. ${ }^{70}$ The reasons for the great gender disparity in EAC incidence are not known. A greater proportion of abdominal fat, or possibly unknown influences of estrogen or testosterone on disease activity and severity are possible explanations..$^{70,79}$

In the immediate future, the incidence of EAC is expected to continue its increase. Kong et al conducted an analysis of 3 models looking at projections of EAC incidence, progression, and mortality. According to recent predictions, the incidence of EAC is expected to rise until at least 2030 in males (see Figure 4). At that point, the estimates place the incidence of EAC at 8.4 to 10.1 per 100,000 person-years. ${ }^{80}$

\section{Selected risk factors for EAC}

GERD-The association between GERD symptoms and EAC risk has been shown to be strong, with risk estimates in those with frequent GERD symptoms ranging from three-fold to five-fold higher or more compared to asymptomatic controls. ${ }^{40,81-83}$ In a pivotal casecontrol study out of Sweden in 1999, Lagergren et al found that compared to individuals without GERD symptoms, those with recurrent symptoms had a risk of EAC more than 7 times higher ${ }^{81}$ Among those with severe and longstanding symptoms, the risk was increased dramatically, by a factor of 43 compared to controls (OR 43.5). This association was also seen in several other studies 40,82 with estimates of the risk of EAC ranging from threefold to fivefold higher in those with GERD. Odds ratios increased with more severe or more frequent symptoms. ${ }^{40,82}$. Pooled data from the BEACON consortium, analyzed by Cook et $\mathrm{al}^{83}$, found similar effects. Those with longer duration of GERD symptoms had an approximately 5-fold increase in risk, and this increased to a six-fold increase with symptoms longer than 20 years. ${ }^{83}$

What can we conclude from this information? The relationship between GERD symptoms and risk of EAC is predictable and robust. Data supporting this relationship are more robust than those supporting the relationship between GERD and BE, in which an inconsistent relationship between symptom severity and risk of disease is seen. ${ }^{21}$ The association between GERD and EAC has been less rigorously studied in minority populations and in women, and estimates of risk may differ when these patient populations are considered.

Obesity-Obesity is a risk factor for development of EAC, and some authorities have suggested that obesity is the central driver of BE and EAC rates in the developed world. ${ }^{30,}{ }^{84}$ However, the initial rise in EAC incidence predated the obesity epidemic, and thus obesity does not fully explain observed EAC incidence trends. ${ }^{85}$ The risk of EAC in patients in the highest categories of BMI has consistently been shown to be 3- to 7-fold higher than those with normal body weight. ${ }^{74,86,87}$ This relationship has been reliably demonstrated in other population-based studies as well, and, remarkably, occurs whether or not reflux is present. Other studies have suggested a linear risk increase with increasing BMI. ${ }^{40,88}$ (see Figure 5). A pooled analysis of 10 case-control studies assessed the relationship between BMI and EAC. Compared with the referent group (BMI <25), increasing BMI was associated with increased risk at cutpoints of 30-34.9(OR 2.39), 35.0 - 
39.9 (OR 2.79), and >40.0 (OR 4.76). ${ }^{89}$ Prospective studies have shown similar trends. In a prospective cohort study design, Abnet et al compared those with BMI 18.5 - 25 (normal body weight) to those with obesity (BMI > 30.0) and found that the risk of EAC was increased by more than a factor of two (HR 2.1). The risk of EAC increased further in those with BMI > 35 (HR 2.64)..$^{90}$

As in BE, the obesity risk in EAC may lie primarily in patients with truncal obesity. In a prospective cohort study, Steffen et al found a RR for EAC of 2.6 when comparing those in the highest quartile of waist circumference versus those in the lower quartile. ${ }^{91}$ This has been corroborated in other recent studies. ${ }^{92}$

Tobacco Use-Smokers are reported to have at least twice the risk of EAC as nonsmokers. ${ }^{52,93}$ However, evidence of a possible dose-response relationship has been somewhat inconsistent. ${ }^{93,} 94$ In 2000, Lagergren et al, in a case-control study, looked at possible dose-dependent effects among nearly 200 patients with EAC and 820 controls. In their study, no dose-response trend was seen for either cigarette smokers or pipe smokers, despite such a relationship being seen with EGJ adenocarcinomas. ${ }^{94}$ More recently, in 2010, Cook et al pooled data on tobacco use and EAC risk in both EAC and EGJ adenocarcinoma from the BEACON consortium ${ }^{93}$. In this sample, an association between smoking and cancer was observed for both EAC (OR 1.96) and EGJ adenocarcinoma (OR 2.18). Risk for EAC by gender differed slightly but were not statistically significantly different - there was a trend toward higher risk in males (OR 2.10 vs. 1.74 in females). In this study, a doseresponse relationship was seen. Heavy smokers had the highest risk, with ORs of 2.7 (male) and 3.6 (female). ${ }^{93}$ These data provide compelling evidence that EAC risk increases with increasing levels of exposure to tobacco. The investigators did not find any modulating effects of GERD or BMI on the effect of smoking and EAC risk.

In summary, smoking for any duration appears to increase risk, and smoking more likely leads to more risk. After quitting, risk likely decreases, but this effect is not immediate. ${ }^{93}$ Much of these observed associations may be due in part to the effects of smoking on both GERD and BE risk. Whether smoking increases the risk of EAC in patients with BE is less clear.

Alcohol-Alcohol is strongly associated with squamous cell carcinoma of the esophagus. However, as is seen with BE, alcohol has been shown to have little correlation with development of EAC. In an analysis comparing 260 controls with 227 EAC cases, Anderson et al found no association between any beverage type or amount of alcohol with development of EAC. ${ }^{95}$ In a pooled analysis across 11 studies, Freedman et al found no increased risk of EAC who use alcohol, irrespective of duration or intensity of use. ${ }^{96}$ The summary ORs indicated slightly reduced risk in low and moderate alcohol use groups (ORs $0.78 \& 0.77$ ) but there was no association between alcohol and EAC in very low or high alcohol-use groups. ${ }^{96}$

Helicobacter pylori-Hp causes gastric cancer ${ }^{97}$, but interestingly the predominance of data suggest that Hp infection is associated with a decreased risk of EAC.$^{98}$ In a case control study, Chow et al observed an inverse correlation between Hp infection and esophageal or 
gastric cardia adenocarcinoma (OR 0.4, 0.2-0.8). ${ }^{57}$ Similar inverse relationships have been shown in other studies. ${ }^{99,100}$ The mechanism by which Hp could reduce risk for EAC is not known. It has been suggested that the bacteria could reduce the secretion of acid from the stomach, either through direct action on parietal cells or through chronic inflammation. ${ }^{100,101}$ It is not also not known what effect, if any, eradication of Hp might have on EAC risk.

NSAIDs-Some reports have indicated a decreased risk of EAC with NSAID use, both with aspirin and other non-aspirin drugs. ${ }^{102,103}$ Observational studies have had conflicting results. ${ }^{104,105}$ A prospective cohort study of 713 patients by Sikkema et al found no association between NSAIDs and cancer risk ${ }^{104}$, while Nguyen et al found a reduced risk of EAC (OR 0.64) in a nested case-control study in $2010^{105}$. Systematic reviews, however, have showed a decreased risk of EAC in those taking NSAIDs. Corley et al found a decreased risk among those using NSAIDs or aspirin (OR 0.57, 95\% CI: $0.47-0.71$ ), ${ }^{103} \mathrm{~A}$ more recent meta-analysis by Abnet et al in 2009 also found an inverse correlation between NSAID use and esophageal adenocarcinoma (OR 0.64, 95\% CI: 0.52-0.79). In summary, EAC risk may be slightly reduced by taking NSAIDs, but the magnitude of risk reduction is small. A more clear pattern in individual studies would make this conclusion more robust.

\section{Progression of BE to EAC}

Earlier estimates had placed the annual rate of progression from BE to EAC at $0.5 \%$, 106 . However, more recent large cohort studies have reported lower rates of progression, ranging from $0.1-0.3 \% .10,11,107$ Clinical guidelines have recommended periodic endoscopic surveillance for the detection of dysplasia and early cancer in patients with BE. However, surveillance becomes less cost-effective at lower EAC risks, and therefore understanding factors associated with progression are key to guiding management.

\section{Dysplasia in BE}

Dysplasia in BE is a histologic diagnosis suggesting that epithelial cells have acquired genetic or epigenetic alterations which predispose them to the development of malignancy. ${ }^{1}$ Dysplasia, when identified in a patient with BE, predicts a higher risk of EAC, but a number of issues have limited its utility. For example, sampling error during surveillance endoscopy is an obstacle that has hindered the effectiveness of dysplasia as an accurate marker of cancer risk. Because dysplasia is not readily distinguished endoscopically from typical BE, an area of dysplastic epithelium can easily be missed. ${ }^{108}$ Thus, even with extensive sampling, by the time histology shows dysplasia, cancer may be present. ${ }^{109}$ Surgical series have shown that cancer was often present at referral for esophagectomy when the referral was for endoscopically-diagnosed high-grade dysplasia. ${ }^{11,108}$ Because of sampling error, guidelines recommend use of the Seattle biopsy protocol, an aggressive biopsy technique that seeks to minimize sampling error and improve reliability of cancer and dysplasia detection ${ }^{110}$. Studies have shown that strict adherence to the Seattle protocol improves detection of HGD and cancer. ${ }^{45}$ After implementing the strict guidelines, a hospital system in the U.K. improved detection of HGD or cancer by more than fourfold. ${ }^{111}$ Despite the benefits of aggressive biopsy protocol, in practice adherence is suboptimal. In a 2009 study 
by Abrams et al looking at a national pathology database, these biopsy guidelines were followed in just over half (51.2\%) of over 2200 BE surveillance cases. ${ }^{112}$ Furthermore, nonadherence was associated with a significant reduction in dysplasia detection (summary OR $0.53)$.

Another issue is the rate of progression. Rates of EAC development in low-grade dysplasia (LGD) were once thought to be as high as $7-8 \%$ or more per year or higher ${ }^{109,113-116}$ More recent estimates place the annual risk of progression in BE with LGD closer to $0.5 \%$ $3 \%$, with some newer estimates even lower ${ }^{117}$. However, these estimates are remarkably heterogeneous. (Table 4) Numerous issues confound the accurate interpretation of the presence and severity of dysplasia in BE. Even among experienced pathologists, the extent of interobserver agreement when diagnosing LGD can be less than 50\%. ${ }^{116,118}$ Other work has shown difficulty in reproducing the diagnosis of $\mathrm{BE}^{119}$. This is due in part to the fact that inflammation can cause cytologic atypia in the bases of crypts that mimics dysplasia. "Regression" of LGD, or the failure to detect dysplastic changes on subsequent endoscopies, also may occur in half or more of patients with LGD. ${ }^{120,121}$ Due to uncertainties regarding LGD-associated cancer risk, there remains debate over the optimal management strategy in these patients. Incidence of EAC or HGD is estimated at $1.1 \%-6 \%$ annually but some estimates are as high as $13.4 \%$ per year ${ }^{10,11,107,122,123}$ With HGD, inter-observer agreement is better but is still less than $90 \% .{ }^{108}$ Given the high cumulative incidence of progression from HGD to EAC, current guidelines recommend endoscopic intervention for such patients. 124,125

\section{Factors that increase risk for dysplasia progression}

The strongest predictor of progression to HGD or EAC is baseline low grade dysplasia. Sikkema et al followed 713 patients with BE with or without LGD for a mean of 4 years, and found that the strongest predictor of incident EAC was the presence of LGD (with OR 9.6) ${ }^{104}$. In longitudinal studies, progression rates are significantly higher in those with LGD, but estimates of increased risk vary widely (See Table 2). Most studies following both nondysplastic barrett's (NDBE) patients and LGD patients have found increased risk in the 4fold to 9-fold range if LGD is present ${ }^{11,126-132}$ but estimates have ranged from 2-fold to 27fold increases in progression rates $10,11,107,108,113,114,121,122,126,127,129-141$

When patients' slides are reviewed by an expert panel of pathologists, the risk of cancer progression increases due to many LGD patients being downstaged to NDBE ${ }^{137,140}$ Curvers et al ${ }^{137}$ found an annual progression rate of $9.4 \%$ in those with LGD confirmed by expert review, compared to an annual risk of $0.53 \%$ who were downstaged to NDBE after review. This was corroborated by Duits et al in 2014. ${ }^{140}$ These investigators found that approximately $75 \%$ of those deemed to have LGD by community pathologists were subsequently downgraded to non-dysplastic reads by expert pathologists. Among the quarter of patients who had their LGD reading confirmed, progression rates were extremely high $9.1 \%$ of these patients progressed to either HGD or EAC on an annual basis.

Duration of BE is also a risk factor for disease progression. Sikkema et al found that the cumulative incidence of HGD or EAC was $9.6 \%$ over 4 years in those with BE duration $>10$ 
years. In those with $\mathrm{BE}$ duration $<10$ years, the cumulative incidence was $3.1 \%$. Incidence was $13.3 \%$ in those with esophagitis compared to $3.0 \%$ in those without. ${ }^{104}$

Among those with HGD, the risk of cancer is substantially higher. Reid et al (Reid 2000) reported a cancer risk of 59\% over 5 years (or $11.8 \%$ annually) in patients with HGD at index endoscopy, compared to $1.5 \%$ annual cancer risk in LGD patients. A meta-analysis published in 2008 yielded a crude incidence rate of $5.6 \%$ across 4 studies, with point estimates of annual incidence rates ranging from $2.3 \%$ per year to $10.3 \%$ per year. ${ }^{142}$ Endoscopic therapy is highly effective for the eradication of BE and associated dysplasia, and is now considered the preferred management strategy for patients with HGD. ${ }^{124}$

In summary, LGD represents a marker of increased risk of progression to cancer in patients with BE. However, the magnitude of risk increase is unclear, as reported progression rates to EAC in LGD have been widely variable. This variability is due in part to the poor reproducibility of this diagnosis. Patients with HGD are at very high risk of progression to cancer, prompting recommendations for therapeutic intervention when it is found. More robust data on progression risk may help better tailor surveillance strategies to each patient in the future.

\section{BE Segment Length}

Other risk factors have been identified that increase the risk of developing EAC in the setting of BE. A number of studies have found that the risk of EAC is greater in longer segments of BE compared to shorter segments ${ }^{112,143,144}$ A study by Weston et al found that the risk increased by a factor of 6 in longer segments. ${ }^{144}$ Sikkema et al, in a prospective study design, found that for every additional $\mathrm{cm}$ of BE, the cumulative risk of HGD or EAC increased by $11 \%$ over 4 years. ${ }^{104}$ The relationship between segment length and increased risk of EAC is not always linear, ${ }^{145}$ but the preponderance of evidence suggests that greater surface area of columnar-lined mucosa correlates with increased cancer risk.

\section{Extent of Dysplasia}

Studies have attempted to determine whether greater extent of dysplasia within a Barrett's segment confers increased risk of neoplastic progression. Interestingly, studies have had conflicting results as to whether or not more extensive LGD or HGD increases the risk of subsequent EAC. ${ }^{107,} 139,146-148$ A study by Srivastava suggested that, when looking at crypts showing dysplasia (as a criteria for LGD diagnosis), increased fractions of dysplastic crypts correlated with an increased EAC risk. ${ }^{146}$ Buttar et al also found a 4-fold higher risk of cancer progression in those with extensive HGD compared to those with unifocal HGD. ${ }^{147}$ However this result could not be duplicated in a follow-up study. ${ }^{148}$ Intuitively, it would seem that the presence of greater numbers of dysplastic crypts would confer an increased risk of future cancer. However, in part due to sampling error limitations of endoscopic surveillance, the utility of focal vs. multifocal dysplasia as a risk stratification tool is unclear. 


\section{Molecular/Biologic Markers for Progression from BE to Dysplasia/Cancer}

Numerous studies have attempted to assess the utility of molecular biomarkers to predict progression and assist with risk stratification. If low risk patients can be accurately identified, then little or no follow-up may be warranted. Alternatively, chemopreventive or endoscopic interventions could be targeted to high-risk patients. However, to date none of the candidate biomarkers has been prospectively validated.

P53 may have the most promise of any of the biomarkers for predicting neoplastic progression in patients with Barrett's. Kastelein et al studied the effect of aberrant p53 expression in a nested case-control study and found striking results. ${ }^{149} \mathrm{P} 53$ overexpression assessed by immunohistochemistry was associated with significantly increased risk of progression to either HGD or EAC (RR 5.6, 95\% CI: 3.1, 10.3). Among those with loss of p53 expression, the risk of progression was even higher (RR 14.0, 95\% CI: 5.3, 37.2). LGD alone was far less predictive of progression (RR 2.4, 95\% CI: 0.9, 6.0), and the positive predictive value of progression was 15\% with LGD alone compared to 33\% in patients with both LGD and aberrant p53 expression. ${ }^{149} \mathrm{P} 53$ has been found to increase the risk of progression in other studies as well. In a prospective cohort study, Reid et al found that loss of heterozygosity ( $\mathrm{LOH})$ of the chromosome harboring p53 was associated with a 7-fold increase in progression risk. ${ }^{150151}$

In a prospective study design, Reid et al analyzed abnormalities in genetic content by flow cytometry and found that, among patients with HGD, incidence of esophageal cancer varied from $58 \%$ over 3 years in patients with baseline cytologic abnormalities, to $7.7 \%$ in those without baseline cytometric changes. ${ }^{108}$ In such lower risk patients, a less invasive management strategy might be warranted. Bird-Lieberman et al performed a retrospective, nested case-control study from a large cohort of patients in Northern Ireland. In that study, low-grade dysplasia, abnormal DNA ploidy, and Aspergillus oryzae lectin (AOL) were all risk factors for progression. Expert LGD contributed significantly, but AOL (OR 3.7) and ploidy (OR 2.8) were also independent predictors of advancement to EAC. ${ }^{152}$

Another retrospective study found that among 322 patients with BE, aneupoloidy and/or tetraploidy, when assessed by flow cytometry, was associated with a RR of 11.7 for neoplastic progression to cancer. ${ }^{153}$

Fluorescence in situ hybridization (FISH) is a method by which a tissue sample can be tested for a panel of genetic abnormalities. ${ }^{154}$ A prospective study by Davelaar et al tested a protocol comparing p53 staining by immunohistochemistry and FISH on brush cytology specimens. ${ }^{155}$ They found that p53 abnormalities detected by immunohistochemistry (OR 17, 95\% 3.2, 96) and FISH (OR 7.3, 95\% CI: 1.3, 41) were both independent predictors of progression. In addition, when both p53 and FISH were used, detection of LGD, HGD, and EAC was 100\% accurate, both p53 and FISH improved the risk stratification capability of p53 alone, and because flow cytometry requires frozen sections of tissue (something rarely done in clinical practice), ${ }^{45}$ the potential for clinical use of FISH may be greater.

Despite the significant advances in biomarker development, significant barriers remain. Of all the biomarkers currently identified, the greatest potential for clinical application may lie 
with assays using p53. p53 can be easily tested, and in multiple studies has been documented to improve the reproducibility of the diagnosis of dysplasia and to predict neoplastic progression. ${ }^{154}$ Due to the imperfect nature of dysplasia alone as a predictor of neoplastic progressions, work on molecular biomarkers continues at a fervent pace. To date, however, no biomarkers are approved for diagnosis or risk stratification, and the most recent guidelines from the American Gastoenterological Association recommend against use of molecular biomarkers for risk stratification. ${ }^{45}$ Recent British Society of Gastroenterology guidelines propose that $\mathrm{p} 53$ immunostaining should be considered, in addition to routine clinical diagnosis, for BE diagnosis. ${ }^{125}$ However, Pathology societies have yet to develop guidelines for the interpretation and reporting of p53 staining by IHC in Barrett's esophagus.

\section{CONCLUSION}

There has been a remarkable rise in the incidence of esophageal adenocarcinoma. In addition, the spectrum of BE and EAC presents multiple challenges to the medical system. Rapidly increasing incidence, high mortality from EAC, and difficulties with risk stratification all are issues to be overcome for effective intervention in this disease state. Some risk factors for $\mathrm{BE}$ and $\mathrm{EAC}$ are modifiable, such as tobacco use and obesity. In addition to these clinical factors, continued rigorous study of appropriate methods for risk stratification continues. Molecular and genetic biomarkers have considerable promise in risk prediction models, and may in the future appear as part of a prognostic panel, designed to help clinicians focus attention on those most at risk.

\section{Acknowledgments}

Relevant Financial Disclosures: Dr. Shaheen receives research funding from Covidien Medical, CSA Medical, NeoGenomics, Takeda Pharmaceuticals and Oncoscope. He is a consultant for Oncoscope. Dr. Abrams receives research funding from Covidien Medical, CSA Medical, C2 Therapeutics, and Trio Medicines. He is also a consultant for $\mathrm{C} 2$ Therapeutics.

This research was funded by T32 DK07634 and K24DK100548.

\section{Abbreviations}

$\begin{array}{ll}\text { BE } & \text { Barrett's esophagus } \\ \text { CEIM } & \text { complete eradication of intestinal metaplasia } \\ \text { CI } & \text { confidence interval } \\ \text { EMR } & \text { endoscopic mucosal resection } \\ \text { EAC } & \text { esophageal adenocarcinoma } \\ \text { HGD } & \text { high grade dysplasia } \\ \text { IND } & \text { indefinite for dysplasia } \\ \text { LGD } & \text { low grade dysplasia } \\ \text { NDBE } & \text { non-dysplastic Barrett's esophagus } \\ \text { OR } & \text { odds ratio }\end{array}$




$\begin{array}{ll}\text { PY } & \text { person-years } \\ \text { RFA } & \text { radiofrequency ablation } \\ \text { LOH } & \text { loss of heterozygosity } \\ \text { NSAID } & \text { non-steroidal anti-inflammatory drug } \\ \text { GERD } & \text { gastroesophageal reflux } \\ \text { Hp } & \text { Helicobacter pylori }\end{array}$

\section{References}

1. Spechler SJ. Barrett's esophagus and esophageal adenocarcinoma: pathogenesis, diagnosis, and therapy. Med Clin North Am. 2002; 86(6):1423-45. vii. [PubMed: 12510459]

2. Shaheen N, Ransohoff DF. Gastroesophageal reflux, Barrett esophagus, and esophageal cancer: scientific review. Jama. 2002; 287(15):1972-1981. [PubMed: 11960540]

3. Blot WJ. Esophageal cancer trends and risk factors. in Seminars in oncology. 1994

4. Daly JM, Karnell LH, Menck HR. National Cancer Data Base report on esophageal carcinoma. Cancer. 1996; 78(8):1820-1828. [PubMed: 8859198]

5. Hesketh PJ, et al. The increasing frequency of adenocarcinoma of the esophagus. Cancer. 1989; 64(2):526-530. [PubMed: 2736498]

6. Cameron AJ, Ott BJ, Payne WS. The incidence of adenocarcinoma in columnar-lined (Barrett's) esophagus. New England Journal of Medicine. 1985; 313(14):857-859. [PubMed: 4033716]

7. Shaheen NJ, Richter JE. Barrett's oesophagus. The Lancet. 2009; 373(9666):850-861.

8. Lund $\mathrm{O}$, et al. Risk stratification and long-term results after surgical treatment of carcinomas of the thoracic esophagus and cardia. A 25-year retrospective study. The Journal of thoracic and cardiovascular surgery. 1990; 99(2):200-209. [PubMed: 2299857]

9. Siegel R, Naishadham D, Jemal A. Cancer statistics, 2013. CA: a cancer journal for clinicians. 2013; 63(1):11-30. [PubMed: 23335087]

10. Hvid-Jensen F, et al. Incidence of adenocarcinoma among patients with Barrett's esophagus. New England Journal of Medicine. 2011; 365(15):1375-1383. [PubMed: 21995385]

11. Bhat $\mathrm{S}$, et al. Risk of malignant progression in Barrett's esophagus patients: results from a large population-based study. Journal of the National Cancer Institute. 2011; 103(13):1049-1057. [PubMed: 21680910]

12. Cameron AJ, et al. Prevalence of columnar-lined (Barrett's) esophagus. Gastroenterology. 1990; 99(4):918-922. [PubMed: 2394347]

13. Ronkainen J, et al. Prevalence of Barrett's esophagus in the general population: an endoscopic study. Gastroenterology. 2005; 129(6):1825-1831. [PubMed: 16344051]

14. Rex DK, et al. Screening for Barrett's esophagus in colonoscopy patients with and without heartburn. Gastroenterology. 2003; 125(6):1670-1677. [PubMed: 14724819]

15. Zagari RM, et al. Gastro-oesophageal reflux symptoms, oesophagitis and Barrett's oesophagus in the general population: the Loiano-Monghidoro study. Gut. 2008; 57(10):1354-1359. [PubMed: 18424568]

16. Westhoff B, et al. The frequency of Barrett's esophagus in high-risk patients with chronic GERD. Gastrointestinal endoscopy. 2005; 61(2):226-231. [PubMed: 15729230]

17. Conio M, et al. Secular trends in the epidemiology and outcome of Barrett's oesophagus in Olmsted County, Minnesota. Gut. 2001; 48(3):304-309. [PubMed: 11171817]

18. Coleman HG, et al. Increasing incidence of Barrett's oesophagus: a population-based study. European journal of epidemiology. 2011; 26(9):739-745. [PubMed: 21671079]

19. van Soest EM, et al. Increasing incidence of Barrett's oesophagus in the general population. Gut. 2005; 54(8):1062-1066. [PubMed: 15857935] 
20. Cameron AJ, Lomboy CT. Barrett's esophagus: age, prevalence, and extent of columnar epithelium. GASTROENTEROLOGY-BALTIMORE THEN PHILADELPHIA. 1992; 103:12411241.

21. Wong A, Fitzgerald RC. Epidemiologic risk factors for Barrett's esophagus and associated adenocarcinoma. Clinical Gastroenterology and Hepatology. 2005; 3(1):1-10. [PubMed: 15645398]

22. van Blankenstein M, et al. Age and sex distribution of the prevalence of Barrett's esophagus found in a primary referral endoscopy center. The American journal of gastroenterology. 2005; 100(3): 568-576. [PubMed: 15743353]

23. Kramer JR, et al. Waist-to-hip ratio, but not body mass index, is associated with an increased risk of Barrett's esophagus in white men. Clinical Gastroenterology and Hepatology. 2013; 11(4):373381. e1. [PubMed: 23220167]

24. Ford AC, et al. Ethnicity, gender, and socioeconomic status as risk factors for esophagitis and Barrett's esophagus. American journal of epidemiology. 2005; 162(5):454-460. [PubMed: 16076833]

25. Abrams JA, et al. Racial and ethnic disparities in the prevalence of Barrett's esophagus among patients who undergo upper endoscopy. Clinical Gastroenterology and Hepatology. 2008; 6(1):3034. [PubMed: 18063419]

26. Cameron AJ, et al. Gastroesophageal reflux disease in monozygotic and dizygotic twins. Gastroenterology. 2002; 122(1):55-59. [PubMed: 11781280]

27. Conio M, et al. Risk factors for Barrett's esophagus: A case-control study. International journal of cancer. 2002; 97(2):225-229.

28. Johansson J, et al. Risk factors for Barrett's oesophagus: a population-based approach. Scandinavian journal of gastroenterology. 2007; 42(2):148-156. [PubMed: 17327933]

29. Anderson LA, et al. Risk factors for Barrett's oesophagus and oesophageal adenocarcinoma: results from the FINBAR study. World Journal of Gastroenterology. 2007; 13(10):1585. [PubMed: 17461453]

30. de Jonge PJF, et al. Barrett's oesophagus: epidemiology, cancer risk and implications for management. Gut. 2013 p. gutjnl-2013-305490.

31. Bansal A, et al. Impact of Measurement of Esophageal Acid Exposure Close to the Gastroesophageal Junction on Diagnostic Accuracy and Event-Symptom Correlation: A Prospective Study Using Wireless Dual pH Monitoring. The American journal of gastroenterology. 2009; 104(12):2918-2925. [PubMed: 19755975]

32. Lacy BE, Chehade R, Crowell MD. A prospective study to compare a symptom-based reflux disease questionnaire to 48-h wireless $\mathrm{pH}$ monitoring for the identification of gastroesophageal reflux (revised 2-26-11). The American journal of gastroenterology. 2011; 106(9):1604-1611. [PubMed: 21691342]

33. Avidan B, et al. Hiatal hernia size, Barrett's length, and severity of acid reflux are all risk factors for esophageal adenocarcinoma. The American journal of gastroenterology. 2002; 97(8):1930 1936. [PubMed: 12190156]

34. Cameron AJ. Barrett's esophagus: prevalence and size of hiatal hernia. The American journal of gastroenterology. 1999; 94(8):2054-2059. [PubMed: 10445527]

35. Eloubeidi MA, Provenzale D. Clinical and demographic predictors of Barrett's esophagus among patients with gastroesophageal reflux disease: a multivariable analysis in veterans. Journal of clinical gastroenterology. 2001; 33(4):306-309. [PubMed: 11588545]

36. Taylor JB, Rubenstein JH. Meta-analyses of the effect of symptoms of gastroesophageal reflux on the risk of Barrett's esophagus. The American journal of gastroenterology. 2010; 105(8):17301737.

37. Brandt MG, Darling GE, Miller L. Symptoms, acid exposure and motility in patients with Barrett's esophagus. Canadian journal of surgery. 2004; 47(1):47.

38. Singh P, Taylor RH, Colin-Jones DG. Esophageal motor dysfunction and acid exposure in reflux esophagitis are more severe if Barrett's metaplasia is present. The American journal of gastroenterology. 1994; 89(3):349-356. [PubMed: 8122643] 
39. El-Serag HB, et al. Proton pump inhibitors are associated with reduced incidence of dysplasia in Barrett's esophagus. The American journal of gastroenterology. 2004; 99(10):1877-1883. [PubMed: 15447744]

40. Wu AH, Tseng CC, Bernstein L. Hiatal hernia, reflux symptoms, body size, and risk of esophageal and gastric adenocarcinoma. Cancer. 2003; 98(5):940-948. [PubMed: 12942560]

41. Lagergren J. Influence of obesity on the risk of esophageal disorders. Nature Reviews Gastroenterology and Hepatology. 2011; 8(6):340-347.

42. Ogden CL, et al. Prevalence of childhood and adult obesity in the United States, 2011-2012. JAMA. 2014; 311(8):806-814. [PubMed: 24570244]

43. Kamat P, et al. Exploring the association between elevated body mass index and Barrett's esophagus: a systematic review and meta-analysis. The Annals of thoracic surgery. 2009; 87(2): 655-662. [PubMed: 19161814]

44. Edelstein ZR, et al. Central adiposity and risk of Barrett's esophagus. Gastroenterology. 2007; 133(2):403-411. [PubMed: 17681161]

45. Spechler SJ, et al. American Gastroenterological Association technical review on the management of Barrett's esophagus. Gastroenterology. 2011; 140(3):e18. [PubMed: 21376939]

46. Kubo A, et al. Sex-specific associations between body mass index, waist circumference and the risk of Barrett's oesophagus: a pooled analysis from the international BEACON consortium. Gut. 2013 p. gutjnl-2012-303753.

47. Berger, NA.; Dannenberg, AJ., editors. Obesity, Inflammation and Cancer. Springer; 2013.

48. Kubo A, et al. Alcohol types and sociodemographic characteristics as risk factors for Barrett's esophagus. Gastroenterology. 2009; 136(3):806-815. [PubMed: 19111726]

49. Steevens J, et al. A prospective cohort study on overweight, smoking, alcohol consumption, and risk of Barrett's esophagus. Cancer Epidemiology Biomarkers \& Prevention. 2010 p. cebp. 0636.2010.

50. Thrift AP, et al. Alcohol and the Risk of Barrett's Esophagus: A Pooled Analysis from the International BEACON Consortium. The American journal of gastroenterology. 2014

51. Thrift AP, et al. No Significant Effects of Smoking or Alcohol Consumption on Risk of Barrett's Esophagus. Digestive diseases and sciences. 2014; 59(1):108-116. [PubMed: 24114046]

52. Lepage $\mathrm{C}$, et al. Epidemiology and risk factors for oesophageal adenocarcinoma. Digestive and Liver Disease. 2013; 45(8):625-629. [PubMed: 23453359]

53. Cook MB, et al. Cigarette smoking increases risk of Barrett's esophagus: an analysis of the Barrett's and Esophageal Adenocarcinoma Consortium. Gastroenterology. 2012; 142(4):744-753. [PubMed: 22245667]

54. Stemmermann GN. Intestinal metaplasia of the stomach. A status report. Cancer. 1994; 74(2):556564. [PubMed: 8033033]

55. El-Serag H, Sonnenberg A. Opposing time trends of peptic ulcer and reflux disease. Gut. 1998; 43(3):327-333. [PubMed: 9863476]

56. Corley DA, et al. Helicobacter pylori infection and the risk of Barrett's oesophagus: a communitybased study. Gut. 2008; 57(6):727-733. [PubMed: 17895354]

57. Chow W-H, et al. An inverse relation between cagA+ strains of Helicobacter pylori infection and risk of esophageal and gastric cardia adenocarcinoma. Cancer research. 1998; 58(4):588-590. [PubMed: 9485003]

58. Vaezi MF, et al. CagA-positive strains of Helicobacter pylori may protect against Barrett's esophagus. The American journal of gastroenterology. 2000; 95(9):2206-2211. [PubMed: 11007219]

59. Wang C, Yuan Y, Hunt RH. Helicobacter pylori infection and Barrett's esophagus: a systematic review and meta-analysis. The American journal of gastroenterology. 2009; 104(2):492-500. [PubMed: 19174811]

60. Goldenberg RL, et al. Epidemiology and causes of preterm birth. The lancet. 2008; 371(9606):7584.

61. Forssell L, et al. Risk of esophagitis among individuals born preterm or small for gestational age. Clinical Gastroenterology and Hepatology. 2012; 10(12):1369-1375. [PubMed: 22989864] 
62. Forssell L, et al. Increased Risk of Barrett's Esophagus Among Individuals Born Preterm or Small for Gestational Age. Clinical Gastroenterology and Hepatology. 2013; 11(7):790-794. [PubMed: 23376800]

63. Forssell L, et al. Risk of oesophageal adenocarcinoma among individuals born preterm or small for gestational age. European Journal of Cancer. 2013; 49(9):2207-2213. [PubMed: 23490653]

64. Leggett CL, et al. Obstructive Sleep Apnea Is a Risk Factor for Barrett's Esophagus. Clinical Gastroenterology and Hepatology. 2014; 12(4):583-588. e1. [PubMed: 24035775]

65. Garcia JM, et al. Circulating Inflammatory Cytokines and Adipokines Are Associated With Increased Risk of Barrett's Esophagus: A Case-Control Study. Clinical Gastroenterology and Hepatology. 2014; 12(2):229-238. e3. [PubMed: 23954649]

66. Bosch A, Frias Z, Caldwell WL. Adenocarcinoma of the esophagus. Cancer. 1979; 43(4):1557-61. [PubMed: 445351]

67. Devesa SS, Blot WJ, Fraumeni JF. Changing patterns in the incidence of esophageal and gastric carcinoma in the United States. Cancer. 1998; 83(10):2049-2053. [PubMed: 9827707]

68. American Cancer Society. Cancer Facts and Figures. Atlanta: American Cancer Society; 2014.

69. Eloubeidi MA, et al. Temporal trends (1973-1997) in survival of patients with esophageal adenocarcinoma in the United States: a glimmer of hope\&quest. The American journal of gastroenterology. 2003; 98(7):1627-1633. [PubMed: 12873590]

70. Nordenstedt H, El-Serag H. The influence of age, sex, and race on the incidence of esophageal cancer in the United States (1992-2006). Scandinavian journal of gastroenterology. 2011; 46(5): 597-602. [PubMed: 21271900]

71. Cook M, Chow W, Devesa S. Oesophageal cancer incidence in the United States by race, sex, and histologic type, 1977-2005. British journal of cancer. 2009; 101(5):855-859. [PubMed: 19672254]

72. Hur C, et al. Trends in esophageal adenocarcinoma incidence and mortality. Cancer. 2013; 119(6): 1149-1158. [PubMed: 23303625]

73. Younes M, et al. Incidence and survival trends of esophageal carcinoma in the United States: racial and gender differences by histological type. Scandinavian journal of gastroenterology. 2002; 37(12):1359-1365. [PubMed: 12523583]

74. Pera M, et al. Epidemiology of esophageal adenocarcinoma. Journal of surgical oncology. 2005; 92(3):151-159. [PubMed: 16299786]

75. Reid BJ, et al. Barrett's oesophagus and oesophageal adenocarcinoma: time for a new synthesis. Nature Reviews Cancer. 2010; 10(2):87-101.

76. Brown LM, Devesa SS, Chow W-H. Incidence of adenocarcinoma of the esophagus among white Americans by sex, stage, and age. Journal of the National Cancer Institute. 2008; 100(16):11841187. [PubMed: 18695138]

77. Vizcaino AP, et al. Time trends incidence of both major histologic types of esophageal carcinomas in selected countries, 1973-1995. International journal of cancer. 2002; 99(6):860-868.

78. El-Serag HB, et al. Gastroesophageal reflux among different racial groups in the United States. Gastroenterology. 2004; 126(7):1692-1699. [PubMed: 15188164]

79. Lagergren J, Nyrén O. Do sex hormones play a role in the etiology of esophageal adenocarcinoma? A new hypothesis tested in a population-based cohort of prostate cancer patients. Cancer Epidemiology Biomarkers \& Prevention. 1998; 7(10):913-915.

80. Thrift AP, Whiteman D. The incidence of esophageal adenocarcinoma continues to rise: analysis of period and birth cohort effects on recent trends. Annals of oncology. 2012; 23(12):3155-3162. [PubMed: 22847812]

81. Lagergren J, et al. Symptomatic gastroesophageal reflux as a risk factor for esophageal adenocarcinoma. New England journal of medicine. 1999; 340(11):825-831. [PubMed: 10080844]

82. Whiteman DC, et al. Combined effects of obesity, acid reflux and smoking on the risk of adenocarcinomas of the oesophagus. Gut. 2008; 57(2):173-180. [PubMed: 17932103]

83. Cook MB, et al. Gastroesophageal Reflux in Relation to Adenocarcinomas of the Esophagus: A Pooled Analysis from the Barrett's and Esophageal Adenocarcinoma Consortium (BEACON). PloS one. 2014; 9(7):e103508. [PubMed: 25075959] 
84. Ryan AM, et al. Obesity, metabolic syndrome and esophageal adenocarcinoma: epidemiology, etiology and new targets. Cancer epidemiology. 2011; 35(4):309-319. [PubMed: 21470937]

85. Abrams JA, et al. Dating the rise of esophageal adenocarcinoma: analysis of Connecticut Tumor Registry data, 1940-2007. Cancer Epidemiology Biomarkers \& Prevention. 2011; 20(1):183-186.

86. Chow W-H, et al. Body mass index and risk of adenocarcinomas of the esophagus and gastric cardia. Journal of the National Cancer Institute. 1998; 90(2):150-155. [PubMed: 9450576]

87. Lagergren J. Adenocarcinoma of oesophagus: what exactly is the size of the problem and who is at risk? Gut. 2005; 54(suppl 1):i1-i5. [PubMed: 15711002]

88. Lagergren J, Bergström R, Nyrén O. Association between body mass and adenocarcinoma of the esophagus and gastric cardia. Annals of internal medicine. 1999; 130(11):883-890. [PubMed: 10375336]

89. Hoyo C, et al. Body mass index in relation to oesophageal and oesophagogastric junction adenocarcinomas: a pooled analysis from the International BEACON Consortium. International journal of epidemiology. 2012; 41(6):1706-1718. [PubMed: 23148106]

90. Abnet CC, et al. A prospective study of BMI and risk of oesophageal and gastric adenocarcinoma. European Journal of Cancer. 2008; 44(3):465-471. [PubMed: 18221867]

91. Steffen A, et al. Anthropometry and esophageal cancer risk in the European prospective investigation into cancer and nutrition. Cancer Epidemiology Biomarkers \& Prevention. 2009; 18(7):2079-2089.

92. Singh S, et al. Central adiposity is associated with increased risk of esophageal inflammation, metaplasia, and adenocarcinoma: a systematic review and meta-analysis. Clinical Gastroenterology and Hepatology. 2013; 11(11):1399-1412. e7. [PubMed: 23707461]

93. Cook MB, et al. Cigarette smoking and adenocarcinomas of the esophagus and esophagogastric junction: a pooled analysis from the international BEACON consortium. Journal of the National Cancer Institute. 2010

94. Lagergren J, et al. The role of tobacco, snuff and alcohol use in the aetiology of cancer of the oesophagus and gastric cardia. International journal of cancer. 2000; 85(3):340-346.

95. Anderson LA, et al. The association between alcohol and reflux esophagitis, Barrett's esophagus, and esophageal adenocarcinoma. Gastroenterology. 2009; 136(3):799-805. [PubMed: 19162028]

96. Freedman ND, et al. Alcohol intake and risk of oesophageal adenocarcinoma: a pooled analysis from the BEACON Consortium. Gut. 2011 p. gut. 2010.233866.

97. Parsonnet J, et al. Helicobacter pylori infection and the risk of gastric carcinoma. New England Journal of Medicine. 1991; 325(16):1127-1131. [PubMed: 1891020]

98. Islami F, Kamangar F. Helicobacter pylori and esophageal cancer risk: a meta-analysis. Cancer Prevention Research. 2008; 1(5):329-338. [PubMed: 19138977]

99. $\mathrm{Wu} \mathrm{AH}$, et al. Role of Helicobacter pylori CagA+ strains and risk of adenocarcinoma of the stomach and esophagus. International journal of cancer. 2003; 103(6):815-821.

100. de Martel C, et al. Helicobacter pylori infection and the risk of development of esophageal adenocarcinoma. Journal of Infectious Diseases. 2005; 191(5):761-767. [PubMed: 15688293]

101. Engel LS, et al. Population attributable risks of esophageal and gastric cancers. Journal of the National Cancer Institute. 2003; 95(18):1404-1413. [PubMed: 13130116]

102. Farrow DC, et al. Use of aspirin and other nonsteroidal anti-inflammatory drugs and risk of esophageal and gastric cancer. Cancer Epidemiology Biomarkers \& Prevention. 1998; 7(2):97102.

103. Corley DA, et al. Protective association of aspirin/NSAIDs and esophageal cancer: a systematic review and meta-analysis. Gastroenterology. 2003; 124(1):47-56. [PubMed: 12512029]

104. Sikkema M, et al. Predictors for neoplastic progression in patients with Barrett's Esophagus: a prospective cohort study. The American journal of gastroenterology. 2011; 106(7):1231-1238. [PubMed: 21577245]

105. Nguyen DM, Richardson P, El-Serag HB. Medications (NSAIDs, statins, proton pump inhibitors) and the risk of esophageal adenocarcinoma in patients with Barrett's esophagus. Gastroenterology. 2010; 138(7):2260-2266. [PubMed: 20188100] 
106. Shaheen NJ, et al. Is there publication bias in the reporting of cancer risk in Barrett's esophagus? Gastroenterology. 2000; 119(2):333-338. [PubMed: 10930368]

107. Wani S, et al. Risk factors for progression of low-grade dysplasia in patients with Barrett's esophagus. Gastroenterology. 2011; 141(4):1179-1186. e1. [PubMed: 21723218]

108. Reid BJ, et al. Predictors of progression to cancer in Barrett's esophagus: baseline histology and flow cytometry identify low-and high-risk patient subsets. The American journal of gastroenterology. 2000; 95(7):1669-1676. [PubMed: 10925966]

109. Levine DS, et al. An endoscopic biopsy protocol can differentiate high-grade dysplasia from early adenocarcinoma in Barrett's esophagus. Gastroenterology. 1993; 105:40-40. [PubMed: 8514061]

110. Wang KK, Sampliner RE. Practice Parameters Committee of the American College of Gastroenterology Updated guidelines 2008 for the diagnosis, surveillance and therapy of Barrett's esophagus. Am J Gastroenterol. 2008; 103(3):788-797. [PubMed: 18341497]

111. Fitzgerald RC, et al. Rigorous surveillance protocol increases detection of curable cancers associated with Barrett's esophagus. Digestive diseases and sciences. 2001; 46(9):1892-1898. [PubMed: 11575441]

112. Abrams JA, et al. Adherence to biopsy guidelines for Barrett's esophagus surveillance in the community setting in the United States. Clinical gastroenterology and hepatology: the official clinical practice journal of the American Gastroenterological Association. 2009; 7(7):736. [PubMed: 19268726]

113. Skacel M, et al. The diagnosis of low-grade dysplasia in Barrett's esophagus and its implications for disease progression. The American journal of gastroenterology. 2000; 95(12):3383-3387. [PubMed: 11151865]

114. Weston AP, et al. p53 protein overexpression in low grade dysplasia (LGD) in Barrett's esophagus: immunohistochemical marker predictive of progression. The American journal of gastroenterology. 2001; 96(5):1355-1362. [PubMed: 11374668]

115. Hameeteman W, et al. Barrett's esophagus: development of dysplasia and adenocarcinoma. Gastroenterology. 1989; 96(5 Pt 1):1249-1256. [PubMed: 2703113]

116. Montgomery E, et al. Dysplasia as a predictive marker for invasive carcinoma in Barrett esophagus: a follow-up study based on 138 cases from a diagnostic variability study. Human pathology. 2001; 32(4):379-388. [PubMed: 11331954]

117. Singh S, et al. Incidence of esophageal adenocarcinoma in Barrett's esophagus with low-grade dysplasia: a systematic review and meta-analysis. Gastrointestinal endoscopy. 2014; 79(6):897909. e4. [PubMed: 24556051]

118. Reid B, et al. Observer variation in the diagnosis of dysplasia in Barrett's esophagus. Human pathology. 1988; 19(2):166-178. [PubMed: 3343032]

119. Meining A, et al. The Munich Barrett follow up study: suspicion of Barrett's oesophagus based on either endoscopy or histology only—what is the clinical significance? Gut. 2004; 53(10): 1402-1407. [PubMed: 15361485]

120. Sharma P, et al. Dysplasia and cancer in a large multicenter cohort of patients with Barrett's esophagus. Clinical Gastroenterology and Hepatology. 2006; 4(5):566-572. [PubMed: 16630761]

121. Gatenby P, et al. Routinely diagnosed low-grade dysplasia in Barrett's oesophagus: a populationbased study of natural history. Histopathology. 2009; 54(7):814-819. [PubMed: 19635100]

122. de Jonge PJ, et al. Risk of malignant progression in patients with Barrett's oesophagus: a Dutch nationwide cohort study. Gut. 2010; 59(8):1030-1036. [PubMed: 20639249]

123. Gaddam S, et al. Persistence of nondysplastic Barrett's esophagus identifies patients at lower risk for esophageal adenocarcinoma: results from a large multicenter cohort. Gastroenterology. 2013; 145(3):548-553. e1. [PubMed: 23714382]

124. Spechler SJ, et al. American Gastroenterological Association medical position statement on the management of Barrett's esophagus. Gastroenterology. 2011; 140(3):1084-1091. [PubMed: 21376940]

125. Fitzgerald RC, et al. British Society of Gastroenterology guidelines on the diagnosis and management of Barrett's oesophagus. Gut. 2014; 63(1):7-42. [PubMed: 24165758] 
126. Conio M, et al. Long-term endoscopic surveillance of patients with Barrett's esophagus. Incidence of dysplasia and adenocarcinoma: a prospective study. The American journal of gastroenterology. 2003; 98(9):1931-1939. [PubMed: 14499768]

127. Dulai GS, et al. Dysplasia and risk of further neoplastic progression in a regional Veterans Administration Barrett's cohort. The American journal of gastroenterology. 2005; 100(4):775783. [PubMed: 15784018]

128. Lim C, et al. Low-grade dysplasia in Barrett's esophagus has a high risk of progression. Endoscopy. 2007; 39(07):581-587. [PubMed: 17611911]

129. Switzer-Taylor V, et al. Barrett's esophagus: a retrospective analysis of 13 years surveillance. Journal of gastroenterology and hepatology. 2008; 23(9):1362-1367. [PubMed: 18205769]

130. den Hoed C, et al. The minimal incubation period from the onset of Barrett's oesophagus to symptomatic adenocarcinoma. British journal of cancer. 2011; 105(2):200-205. [PubMed: 21673678]

131. Rugge M, et al. Barrett's esophagus and adenocarcinoma risk: the experience of the NorthEastern Italian Registry (EBRA). Annals of surgery. 2012; 256(5):788-795. [PubMed: 23095623]

132. Picardo S, et al. A Barrett's esophagus registry of over 1000 patients from a specialist center highlights greater risk of progression than population-based registries and high risk of low grade dysplasia. Diseases of the Esophagus. 2014

133. Schnell TG, et al. Long-term nonsurgical management of Barrett's esophagus with high-grade dysplasia. Gastroenterology. 2001; 120(7):1607-1619. [PubMed: 11375943]

134. Vieth M, et al. Frequency of Barrett's neoplasia after initial negative endoscopy with biopsy: a long-term histopathological follow-up study. Endoscopy. 2006; 38(12):1201-1205. [PubMed: 17163319]

135. Alcedo J, et al. Trends in Barrett's esophagus diagnosis in Southern Europe: implications for surveillance. Diseases of the Esophagus. 2009; 22(3):239-248. [PubMed: 19425201]

136. Wong T, Tian J, Nagar AB. Barrett's surveillance identifies patients with early esophageal adenocarcinoma. The American journal of medicine. 2010; 123(5):462-467. [PubMed: 20399324]

137. Curvers WL, et al. Low-grade dysplasia in Barrett's esophagus: overdiagnosed and underestimated. The American journal of gastroenterology. 2010; 105(7):1523-1530. [PubMed: 20461069]

138. Jung KW, et al. Epidemiology and natural history of intestinal metaplasia of the gastroesophageal junction and Barrett's esophagus: a population-based study. The American journal of gastroenterology. 2011; 106(8):1447-1455. [PubMed: 21483461]

139. Schouten LJ, et al. Total cancer incidence and overall mortality are not increased among patients with Barrett's esophagus. Clinical Gastroenterology and Hepatology. 2011; 9(9):754-761. [PubMed: 21570484]

140. Duits LC, et al. Barrett's oesophagus patients with low-grade dysplasia can be accurately riskstratified after histological review by an expert pathology panel. Gut. 2014 p. gutjnl-2014-307278.

141. Thota PN, et al. Risk Stratification of Patients With Barrett's Esophagus and Low-grade Dysplasia or Indefinite for Dysplasia. Clinical Gastroenterology and Hepatology. 2014

142. Rastogi A, et al. Incidence of esophageal adenocarcinoma in patients with Barrett's esophagus and high-grade dysplasia: a meta-analysis. Gastrointestinal endoscopy. 2008; 67(3):394-398. [PubMed: 18045592]

143. Wani S, et al. Patients with nondysplastic Barrett's esophagus have low risks for developing dysplasia or esophageal adenocarcinoma. Clinical Gastroenterology and Hepatology. 2011; 9(3): 220-227. e1. [PubMed: 21115133]

144. Weston AP, Badr AS, Hassanein RS. Prospective multivariate analysis of clinical, endoscopic, and histological factors predictive of the development of Barrett's multifocal high-grade dysplasia or adenocarcinoma. The American journal of gastroenterology. 1999; 94(12):34133419. [PubMed: 10606296] 
145. Gatenby PA, et al. Short segment columnar-lined oesophagus: an underestimated cancer risk? A large cohort study of the relationship between Barrett's columnar-lined oesophagus segment length and adenocarcinoma risk. European journal of gastroenterology \& hepatology. 2007; 19(11):969-975. [PubMed: 18049166]

146. Srivastava A, et al. Extent of low-grade dysplasia is a risk factor for the development of esophageal adenocarcinoma in Barrett's esophagus. The American journal of gastroenterology. 2007; 102(3):483-493. [PubMed: 17338734]

147. Buttar NS, et al. Extent of high-grade dysplasia in Barrett's esophagus correlates with risk of adenocarcinoma. Gastroenterology. 2001; 120(7):1630-1639. [PubMed: 11375945]

148. Dar M, et al. Can extent of high grade dysplasia in Barrett's oesophagus predict the presence of adenocarcinoma at oesophagectomy? Gut. 2003; 52(4):486-489. [PubMed: 12631655]

149. Kastelein F, et al. Aberrant p53 protein expression is associated with an increased risk of neoplastic progression in patients with Barrett's oesophagus. Gut. 2012 p. gutjnl-2012-303594.

150. Reid BJ, et al. Predictors of progression in Barrett's esophagus II: baseline 17p (p53) loss of heterozygosity identifies a patient subset at increased risk for neoplastic progression. The American journal of gastroenterology. 2001; 96(10):2839-2848. [PubMed: 11693316]

151. Allison RK, et al. Studies on the photosynthetic reaction. I. The assimilation of acetate by Nostoc muscorum. J Biol Chem. 1953; 204(1):197-205. [PubMed: 13084591]

152. Bird-Lieberman EL, et al. Population-based study reveals new risk-stratification biomarker panel for Barrett's esophagus. Gastroenterology. 2012; 143(4):927-935. e3. [PubMed: 22771507]

153. Rabinovitch PS, et al. Predictors of progression in Barrett's esophagus III: baseline flow cytometric variables. The American journal of gastroenterology. 2001; 96(11):3071-3083. [PubMed: 11721752]

154. Timmer M, et al. Predictive biomarkers for Barrett's esophagus: so near and yet so far. Diseases of the Esophagus. 2013; 26(6):574-581. [PubMed: 23316980]

155. Davelaar AL, et al. Aberrant TP53 detected by combining immunohistochemistry and DNA-FISH improves Barrett's esophagus progression prediction: A prospective follow-up study. Genes, Chromosomes and Cancer. 2014

156. Gerson LB, Shetler K, Triadafilopoulos G. Prevalence of Barrett's esophagus in asymptomatic individuals. Gastroenterology. 2002; 123(2):461-467. [PubMed: 12145799]

157. Ward EM, et al. Barrett's esophagus is common in older men and women undergoing screening colonoscopy regardless of reflux symptoms. The American journal of gastroenterology. 2006; 101(1):12-17. [PubMed: 16405528]

158. Zou D, et al. Epidemiology of symptom-defined gastroesophageal reflux disease and reflux esophagitis: the systematic investigation of gastrointestinal diseases in China (SILC). Scandinavian journal of gastroenterology. 2011; 46(2):133-141. [PubMed: 20955088]

159. Cook M, Wild C, Forman D. A systematic review and meta-analysis of the sex ratio for Barrett's esophagus, erosive reflux disease, and nonerosive reflux disease. American journal of epidemiology. 2005; 162(11):1050-1061. [PubMed: 16221805]

160. Corley DA, et al. Abdominal obesity and body mass index as risk factors for Barrett's esophagus. Gastroenterology. 2007; 133(1):34-41. [PubMed: 17631128]

161. Abnet C, et al. Non-steroidal anti-inflammatory drugs and risk of gastric and oesophageal adenocarcinomas: results from a cohort study and a meta-analysis. British journal of cancer. 2009; 100(3):551-557. [PubMed: 19156150]

162. Kong CY, et al. Exploring the Recent Trend in Esophageal Adenocarcinoma Incidence and Mortality Using Comparative Simulation Modeling. Cancer Epidemiology Biomarkers \& Prevention. 2014; 23(6):997-1006. 


\section{Key Points}

1. Barrett's esophagus is a precursor to esophageal adenocarcinoma

2. The incidence of esophageal adenocarcinoma has increased dramatically and is the most common form of esophageal cancer in the U.S.

3. The strongest risk factor for Barrett's esophagus is gastroesophageal reflux (GERD), however central adiposity and tobacco smoking also increase risk.

4. Risk factors for esophageal adenocarcinoma include GERD, tobacco somking, and obesity, while Helicobacter pylori and NSAIDs may be protective.

5. Dysplastic changes seen on biopsy predict progression of Barrett's to esophageal adenocarcinoma, but estimates of the incidence of EAC in dysplastic Barrett's epithelium vary 


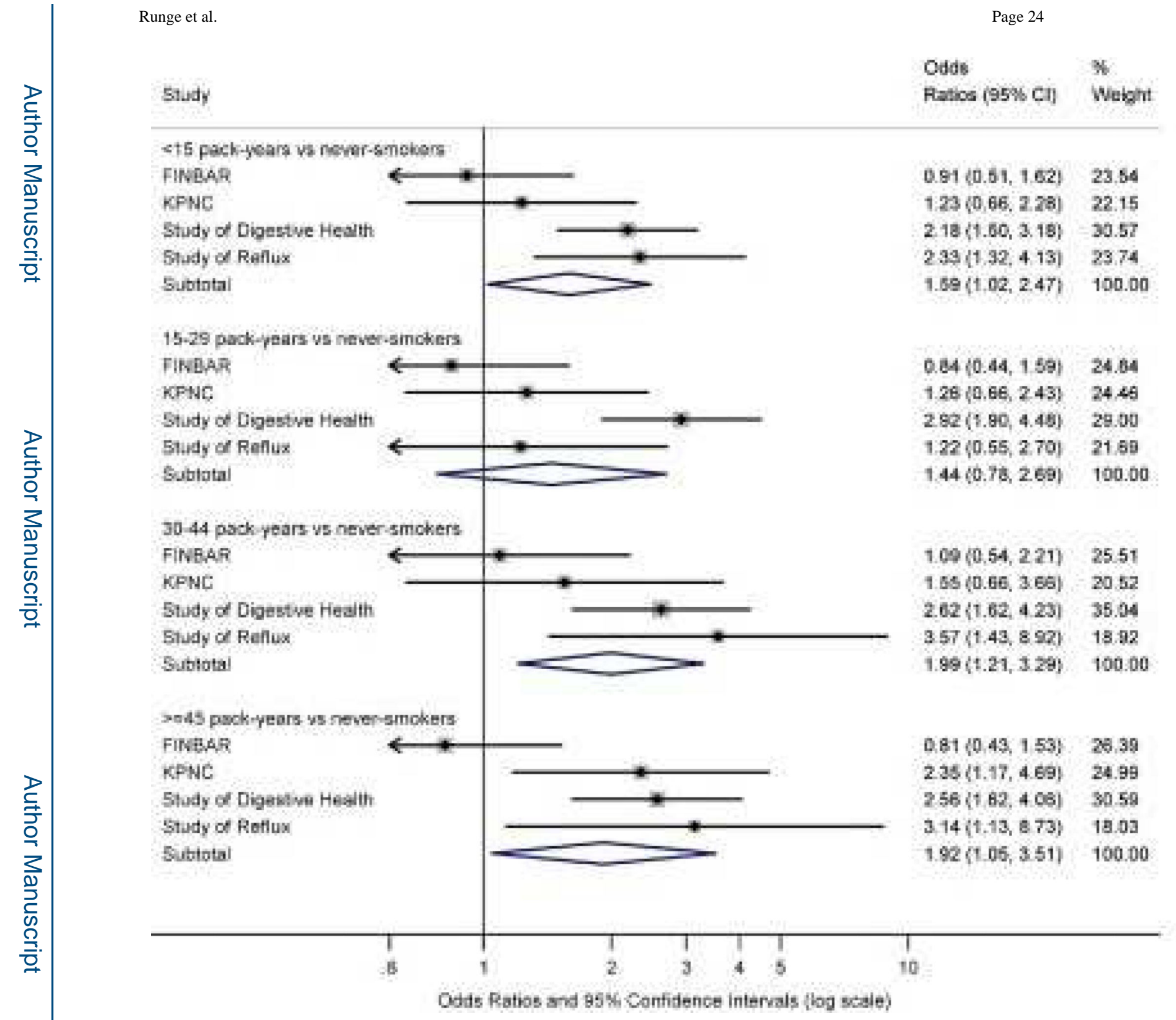

Figure 1.

Forrest plots summarizing the association between smoking and the risk of BE, using population controls. Smoking exposure is grouped by categories. Large unfilled diamonds represent the pooled estimates across all studies within that category. The width of the diamonds represents the 95\% CIs. Black squares indicate the point estimate for each individual study. KPNC, Kaiser Permanente Northern California; UNC, University of North Carolina. Adapted from Cook et al, "Cigarette Smoking Increases Risk of Barrett's Esophagus: An Analysis of the Barrett's and Esophageal Adenocarcinoma Consortium." Gastroenterol 142 (2012): 744-753; with permission. 


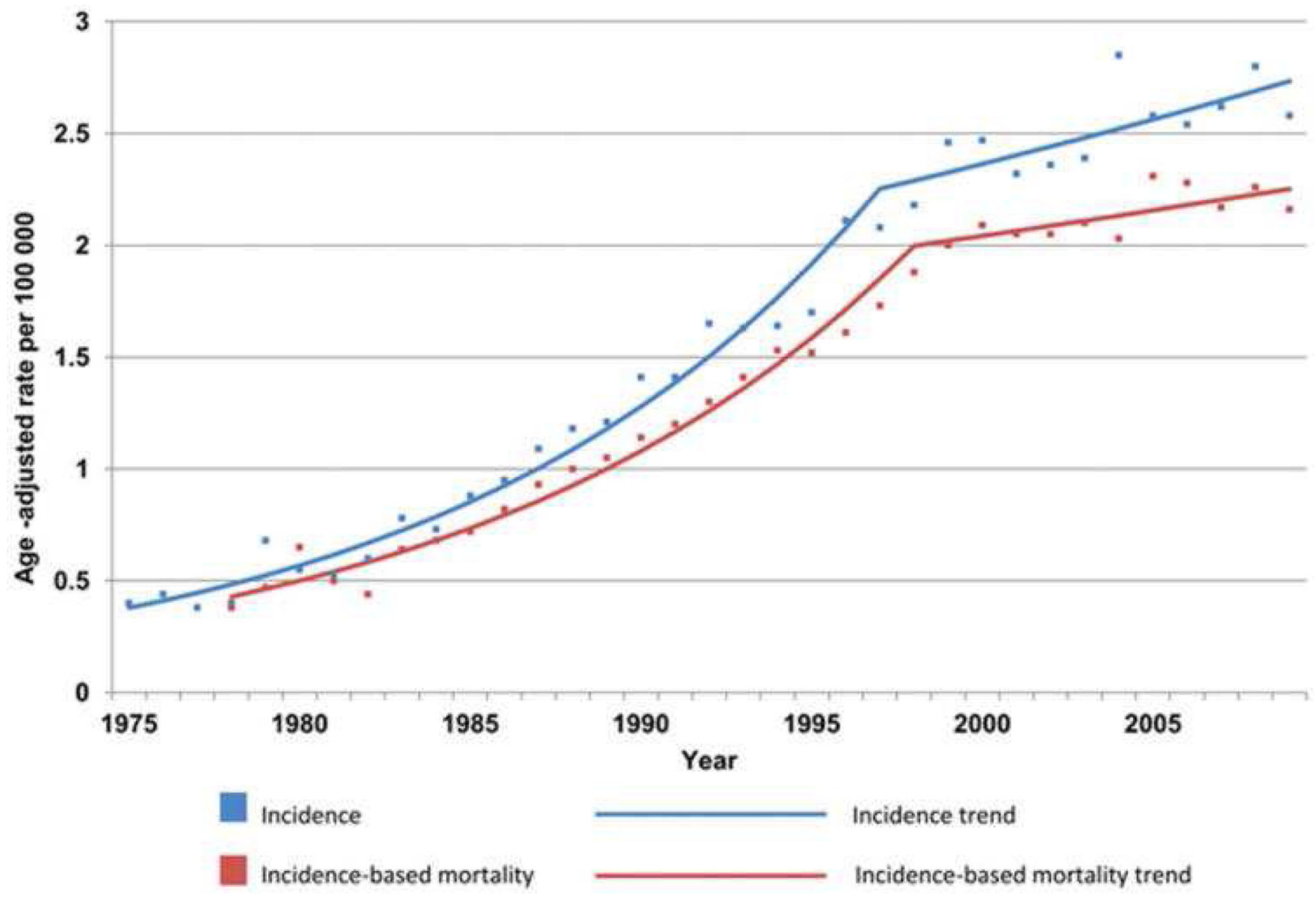

Figure 2.

Incidence and Incidence-based mortality from esophageal adenocarcinoma, $1975-2009$.

Produced from SEER 9 data. From Hur et al "Trends in Esophageal Adenocarcinoma Incidence and Mortality," Cancer 119(6): 1149-58; with permission. 
A

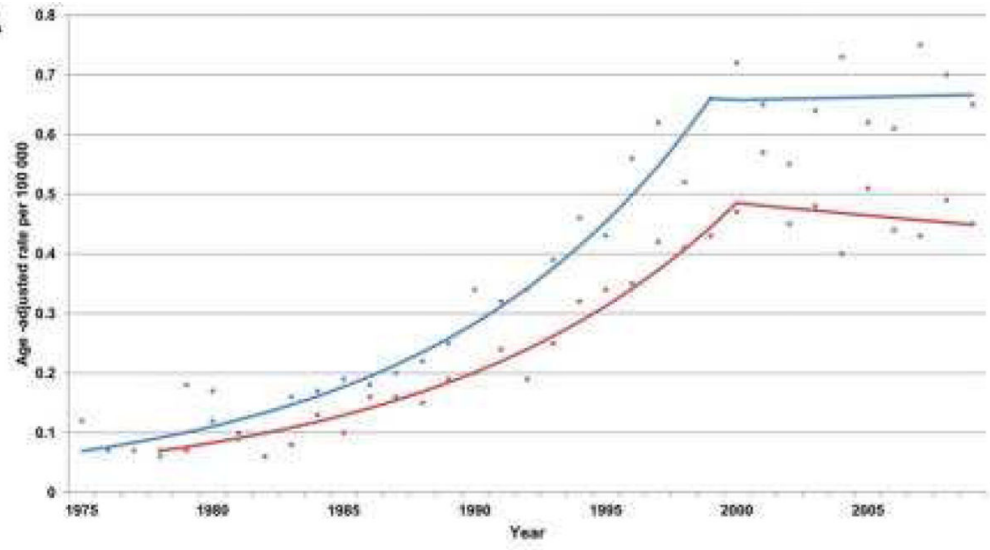

B

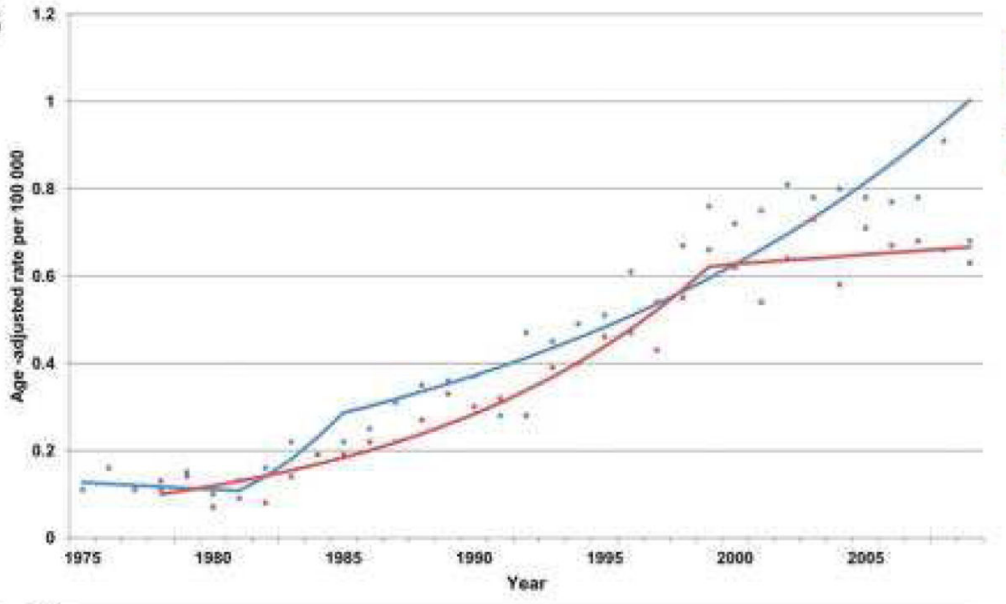

c

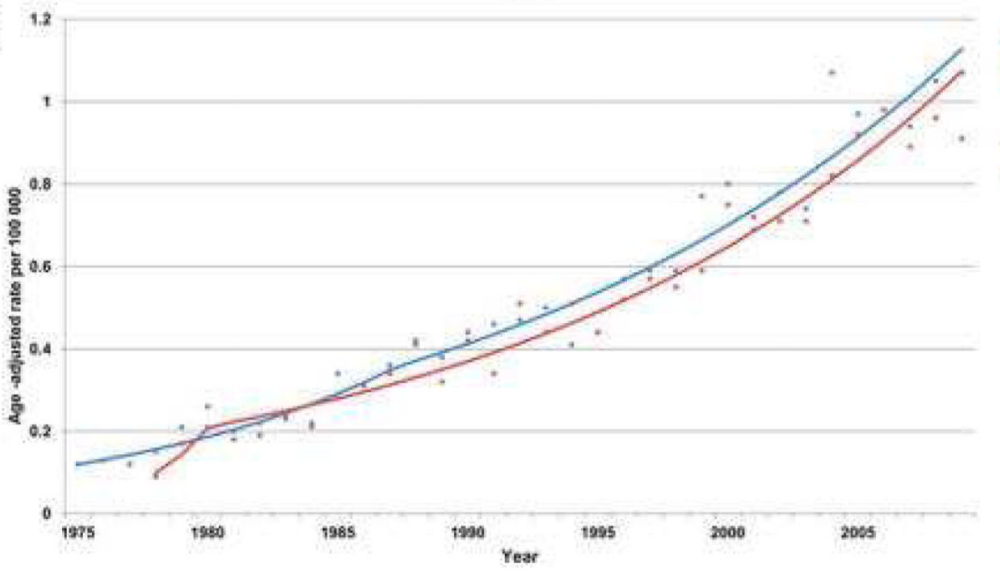

E Inoidenos

E incidence bused motaity

inoderce teent

thoidence byied mansity trend

Figure 3.

Incidence and incidence-based mortality by stage, for (A) Local, (B) Regional, and (C) Distant spread of disease. Produced from SEER 9 data. From Hur et al "Trends in Esophageal Adenocarcinoma Incidence and Mortality," Cancer 119 (6): 1149-58; with permission. 


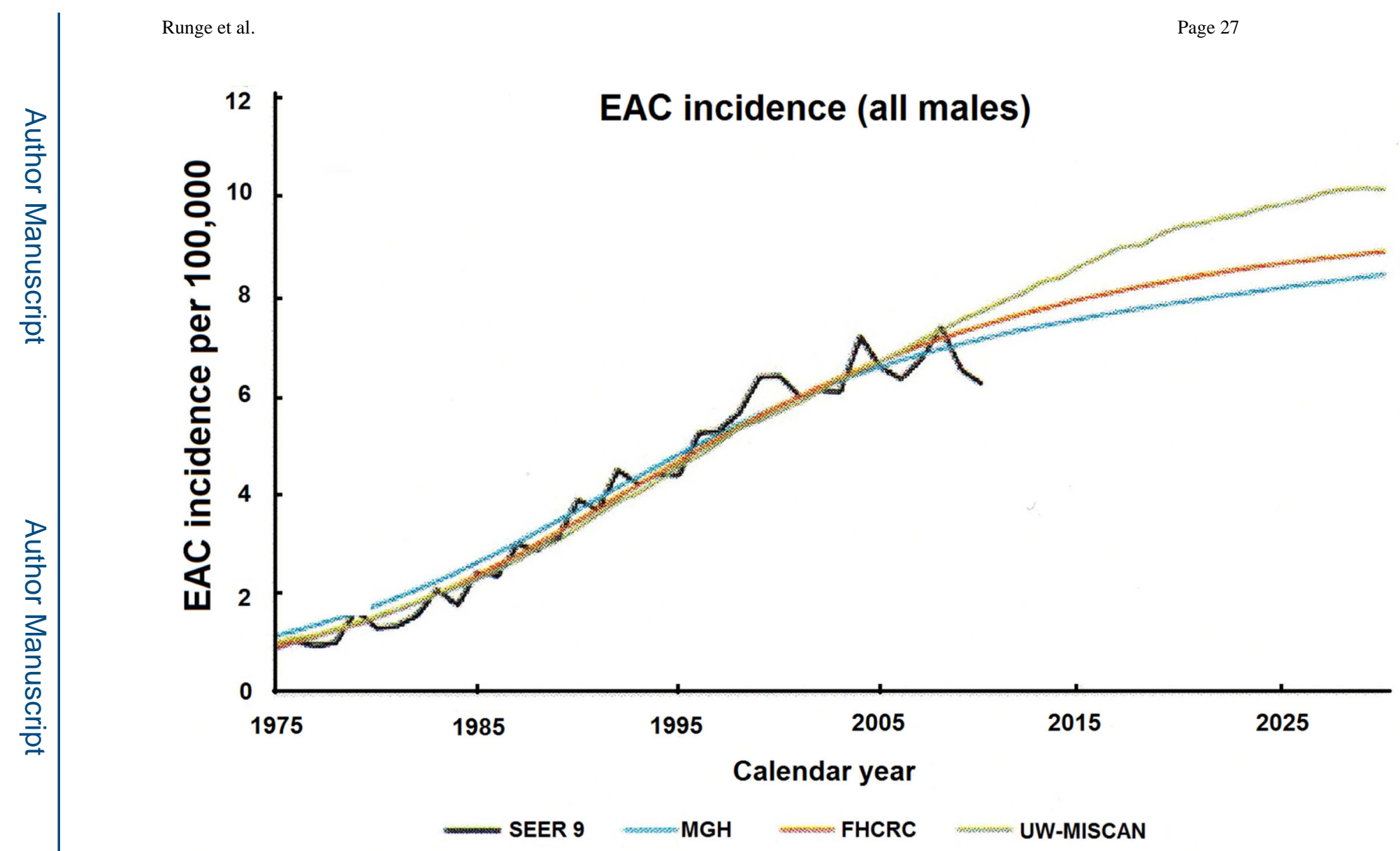

Figure 4.

Predicted incidence rates of EAC through 2030 for all males. Figure depicts yearly SEER data (black line) overlying simulation models from Massachusetts General Hospital (MGH) and the Fred Hutchinson Cancer Research Center (FHCRH), as well as the University of Washington and the Microsimulation Screening Analysis model (UW-MISCAN). From Kong et al, "Exploring the recent trend in esophageal adenocarcinoma incidence and mortality using comparative simulation modeling." Cancer Epidemiol Biomarkers 23 (2014): 997-1006; with permission. 


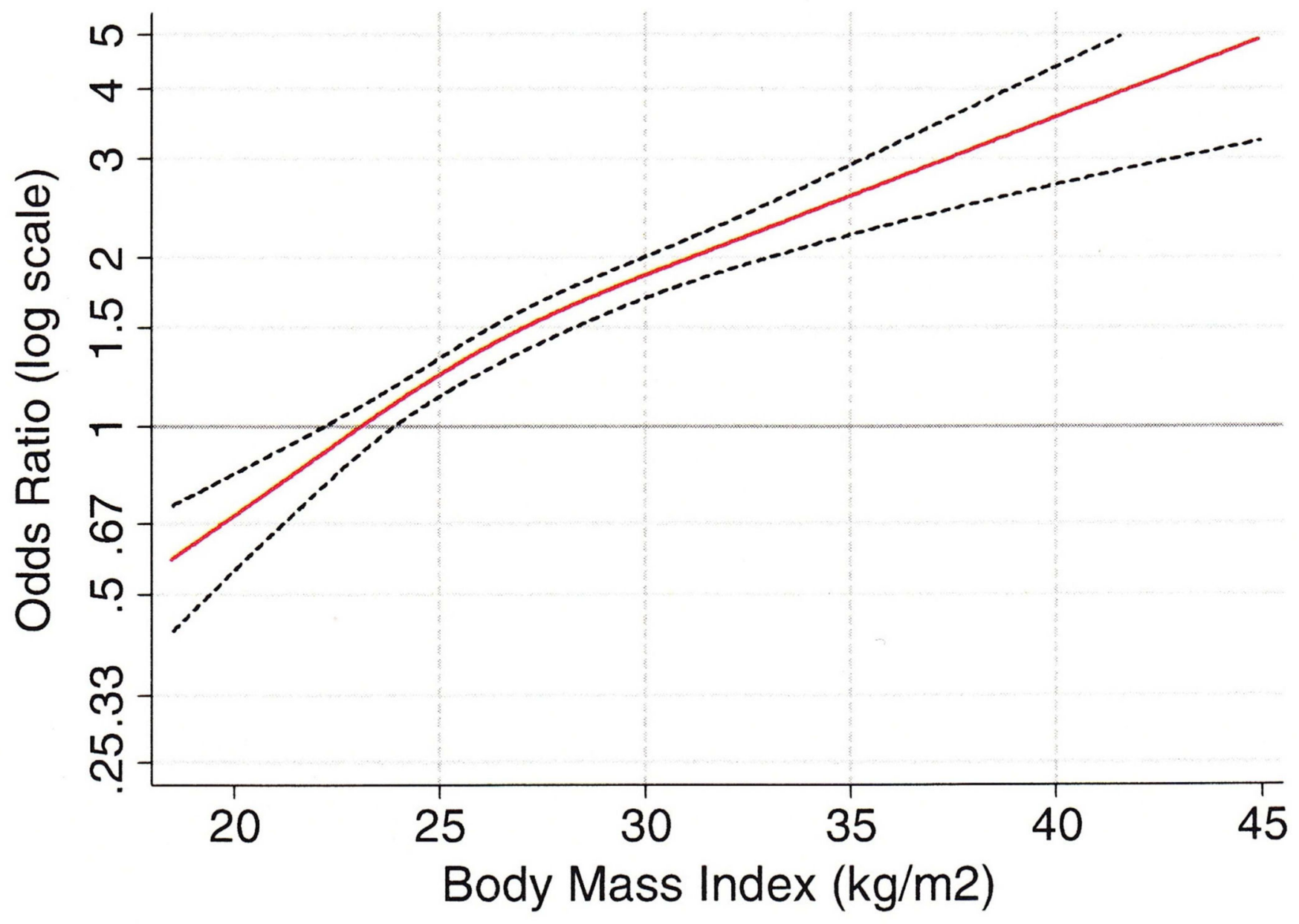

Figure 5.

Restricted cubic regression splines depicting the relationship between body mass index and adenocarcinomas of the esophagus and esophageal junction.

From Hoyo et al, "Body mass index in relation to oesophageal and oesophagogastric junction adenocarcinomas: a pooled analysis from the international BEACON consortium." Int J. Epidemiol 41 (2012): 1706-1718; with permission. 


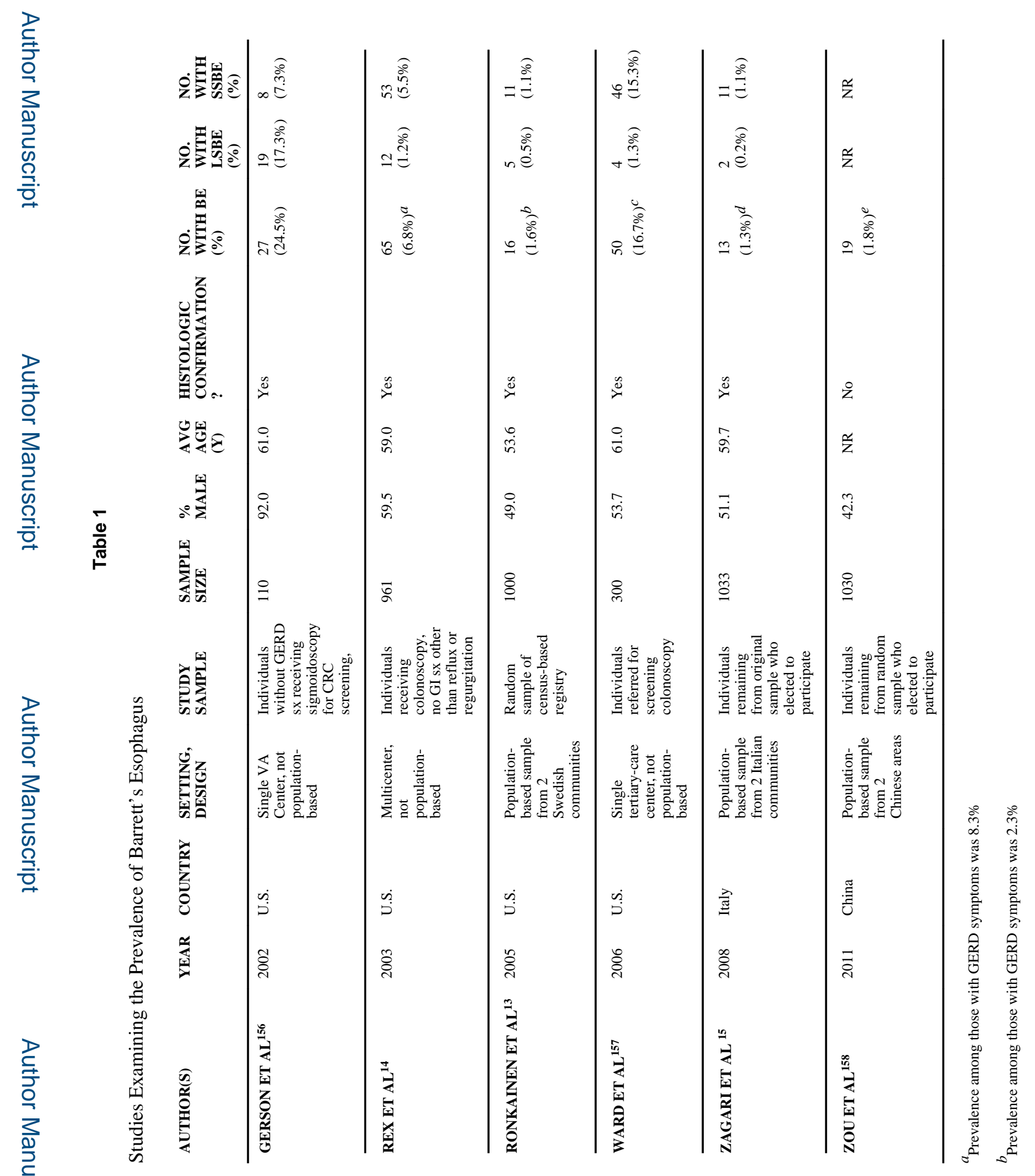



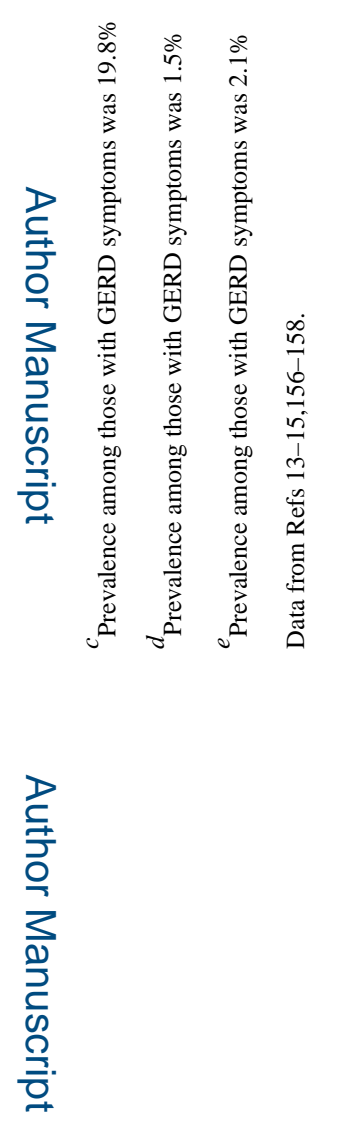

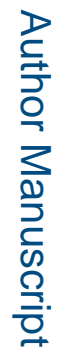

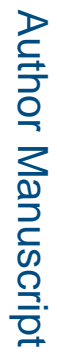

Gastroenterol Clin North Am. Author manuscript; available in PMC 2016 June 01. 


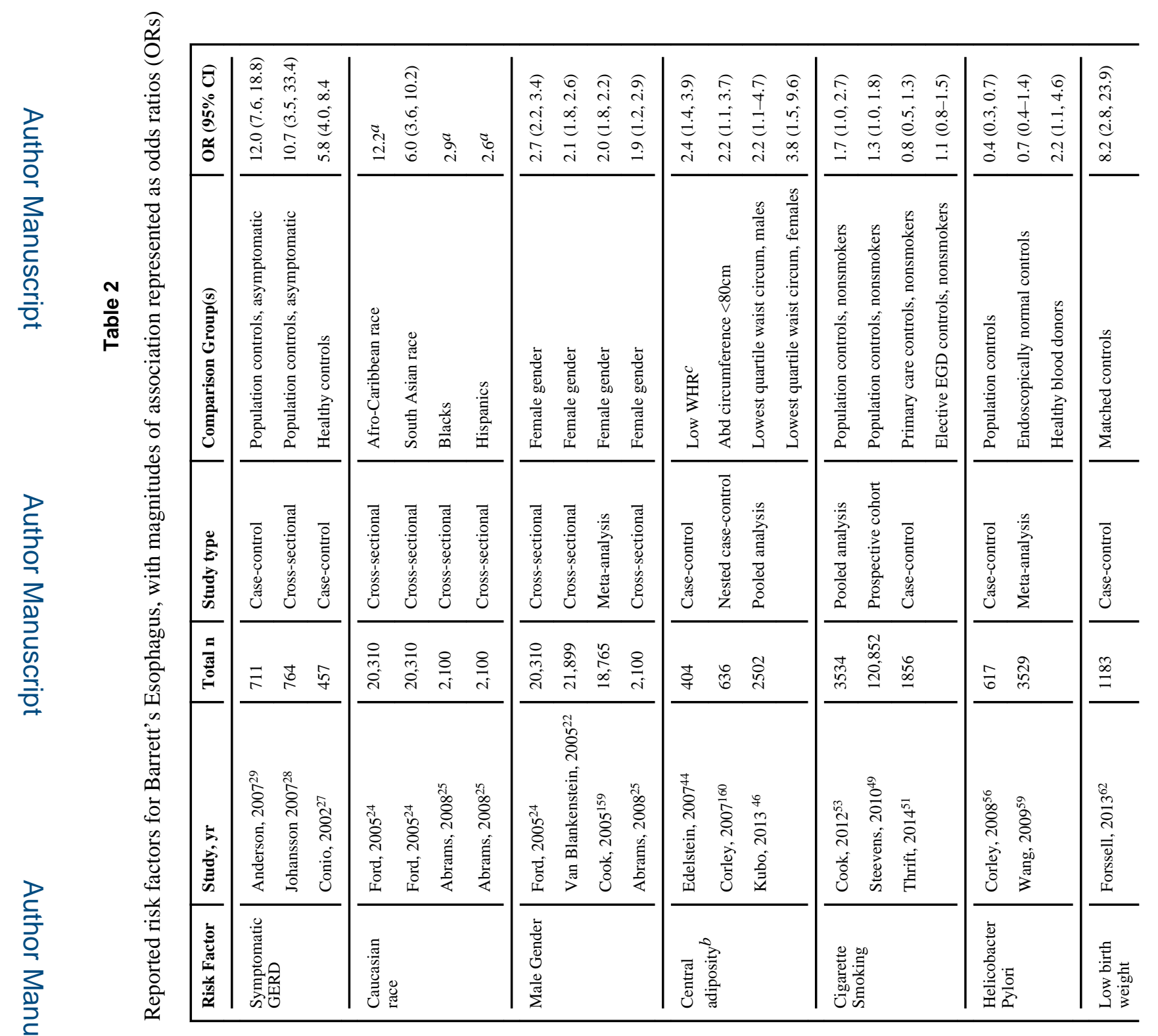

Gastroenterol Clin North Am. Author manuscript; available in PMC 2016 June 01. 

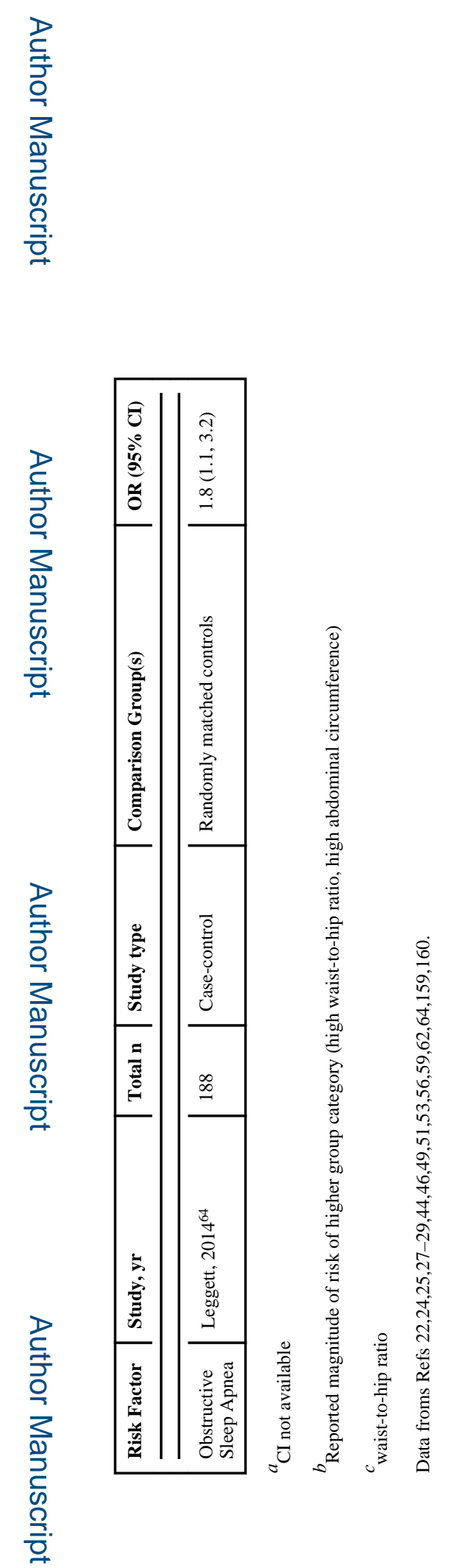

Gastroenterol Clin North Am. Author manuscript; available in PMC 2016 June 01. 


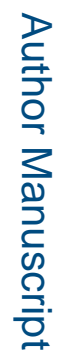

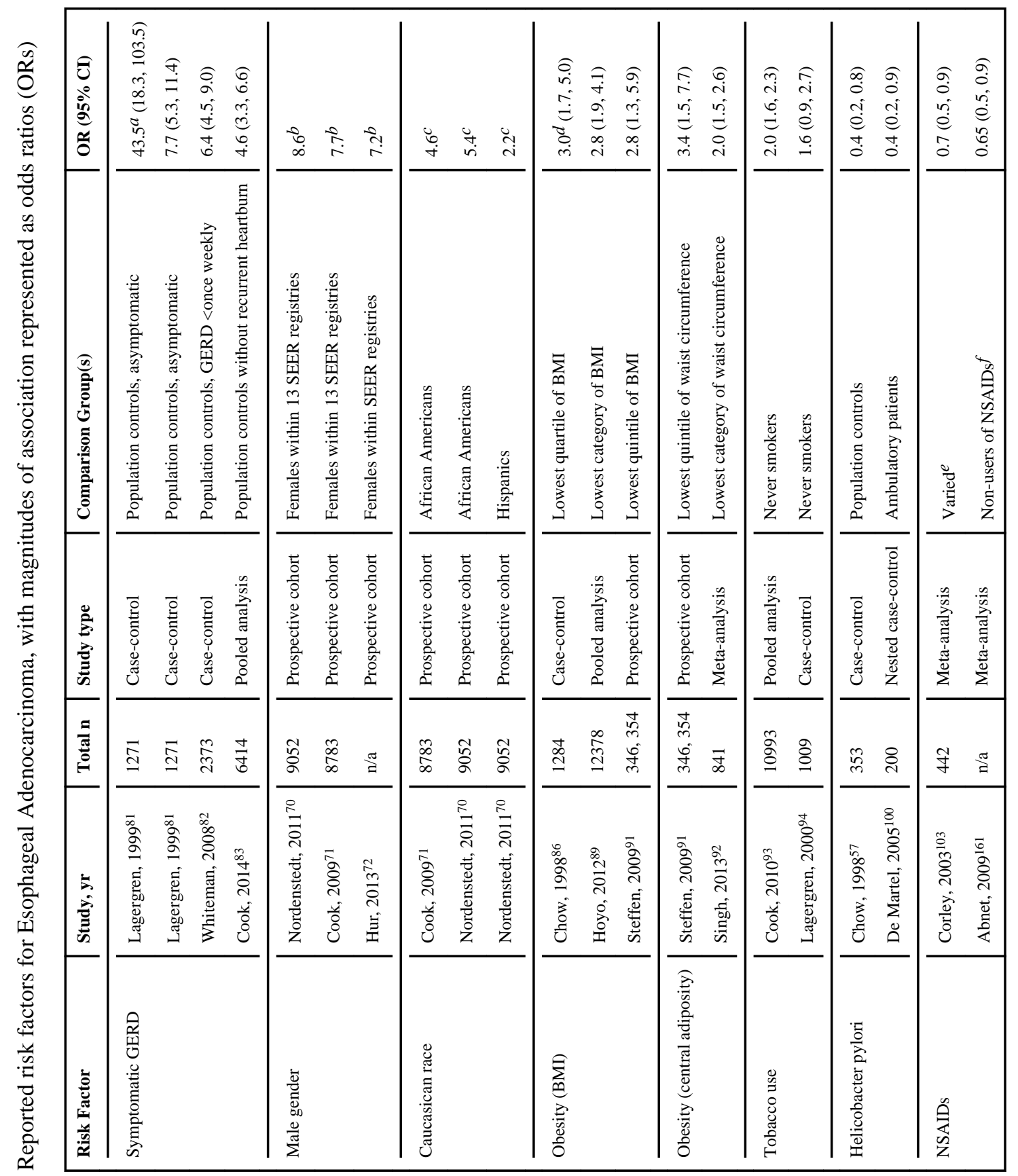



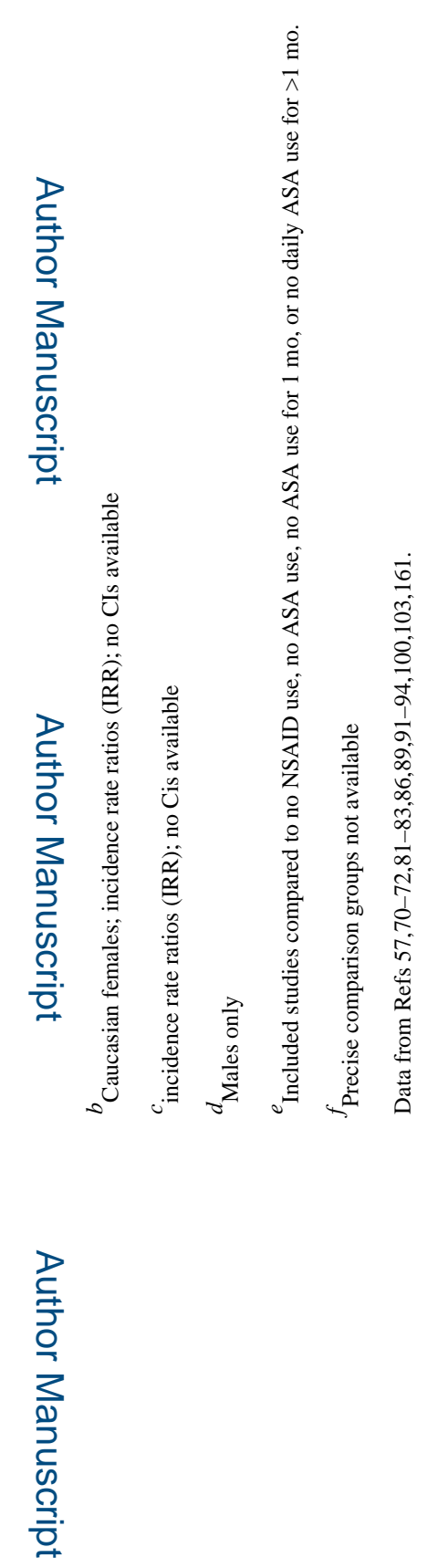

로을 


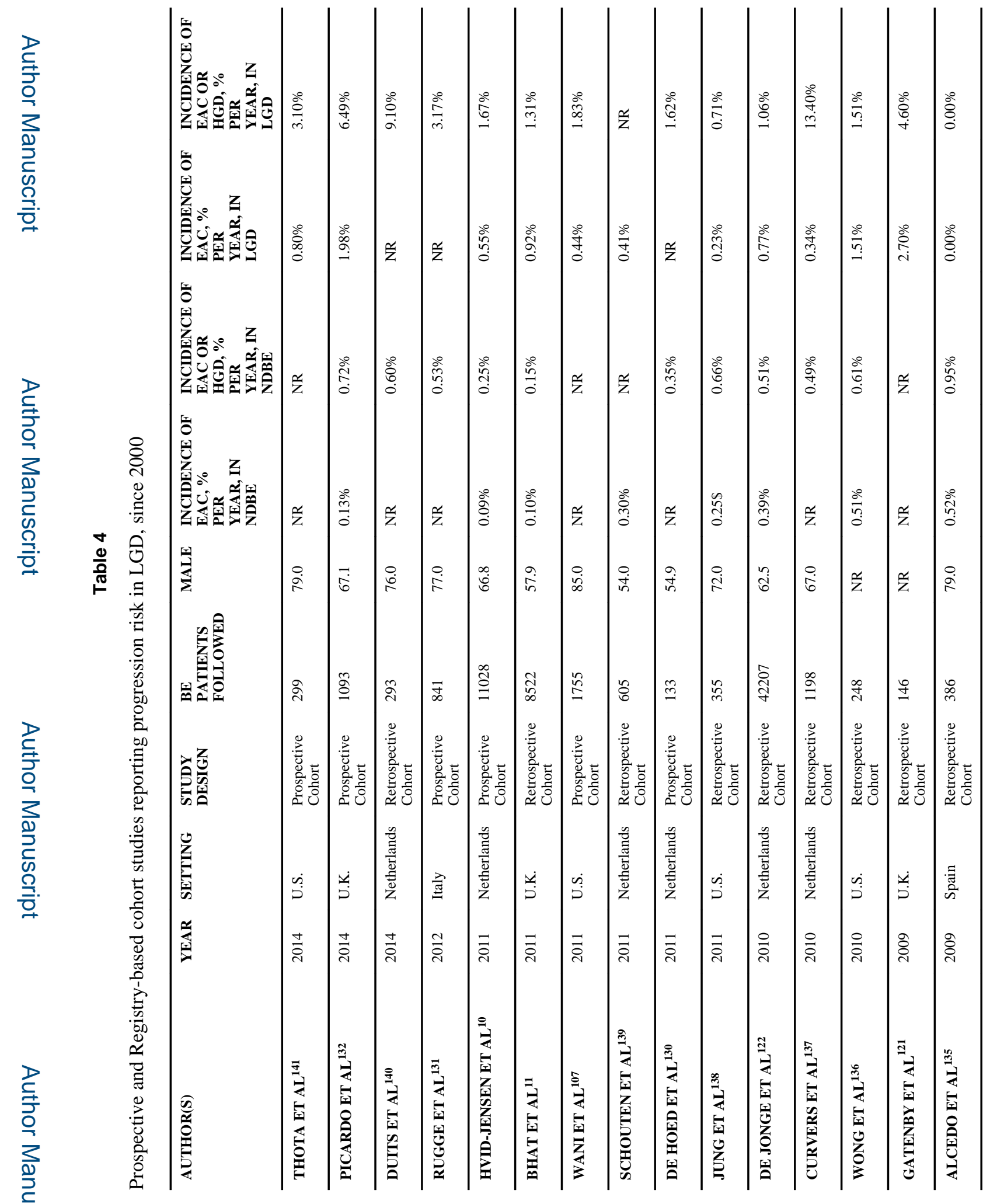

Gastroenterol Clin North Am. Author manuscript; available in PMC 2016 June 01. 


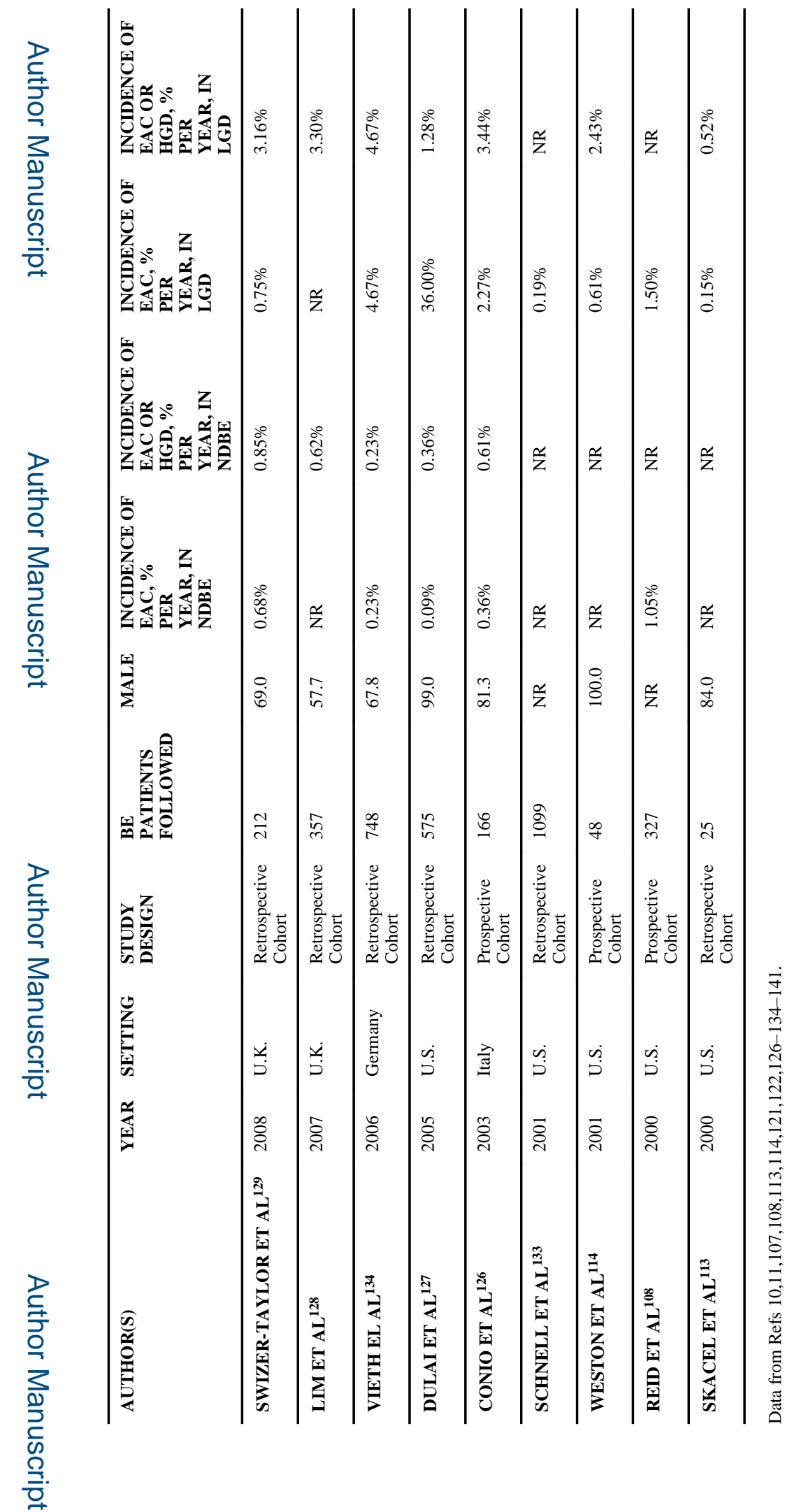

